\title{
Emerging COVID-19 Neurological Manifestations: Present Outlook and Potential Neurological Challenges in COVID-19 Pandemic
}

\author{
Saikat Dewanjee ${ }^{1}$ (D) Jayalakshmi Vallamkondu ${ }^{2} \cdot$ Rajkumar Singh Kalra $^{3,11}$ (D) Nagaprasad Puvvada ${ }^{4}$. \\ Ramesh Kandimalla ${ }^{4,5}$ (1) P. Hemachandra Reddy $6,7,8,9,10$ (1)
}

Received: 9 May 2021 / Accepted: 7 June 2021 / Published online: 24 June 2021

(c) The Author(s), under exclusive licence to Springer Science+Business Media, LLC, part of Springer Nature 2021

\begin{abstract}
The unremitting coronavirus disease 2019 (COVID-19) pandemic caused by the novel severe acute respiratory syndrome coronavirus 2 (SARS-CoV-2) marked a year-long phase of public health adversaries and has severely compromised healthcare globally. Early evidence of COVID-19 noted its impact on the pulmonary and cardiovascular functions, while multiple studies in recent time shed light on its substantial neurological complications, though a comprehensive understanding of the cause(s), the mechanism(s), and their neuropathological outcomes is scarce. In the present review, we conferred evidence of neurological complications in COVID-19 patients and shed light on the SARS-CoV-2 infection routes including the hematogenous, direct/neuronal, lymphatic tissue or cerebrospinal fluid, or infiltration through infected immune cells, while the underlying mechanism of SARS-CoV-2 invasion to the central nervous system (CNS) was also discussed. In an up-to-date manner, we further reviewed the impact of COVID-19 in developing diverse neurologic manifestations associated with CNS, peripheral nervous system (PNS), skeletal muscle, and also pre-existing neurological diseases, including Alzheimer's disease, Parkinson's disease, multiple sclerosis, epilepsy, and myasthenia gravis. Furthermore, we discussed the involvement of key factors including age, sex, comorbidity, and disease severity in exacerbating the neurologic manifestations in COVID-19 patients. An outlook of present therapeutic strategies and state of existing challenges in COVID-19 management was also accessed. Conclusively, the present report provides a comprehensive review of COVID-19-related neurological complications and emphasizes the need for their early clinical management in the ongoing COVID-19 pandemic.
\end{abstract}

Keywords COVID-19 $\cdot$ SARS-CoV-2 $\cdot$ CNS $\cdot$ PNS $\cdot$ Neuroinvasion $\cdot$ COVID-19 pandemic $\cdot$ Neurological complications

\begin{abstract}
Highlights
- Coronavirus disease 2019 (COVID-19)-associated complications involve substantial neurological manifestations.

- SARS-CoV-2 infection routes include the hematogenous, neuronal, lymphatic tissue/cerebrospinal fluid, or infiltration through infected immune cells.

- COVID-19 promotes neurologic manifestations associated with the central and peripheral nervous system and exacerbates the pre-existing neurological and neurodegenerative conditions.

- Patient's age, sex, comorbidity, and severity of the infection are key factors that determine the extent of neurologic manifestations in COVID-19 patients.
\end{abstract}

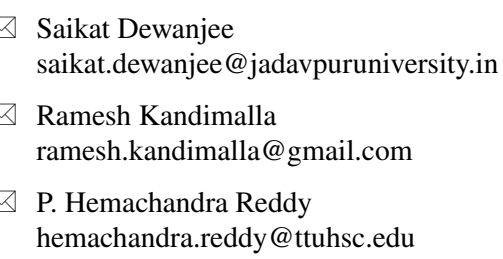

Saikat Dewanjee

saikat.dewanjee@jadavpuruniversity.in

Ramesh Kandimalla

ramesh.kandimalla@gmail.com

P. Hemachandra Reddy

hemachandra.reddy@ttuhsc.edu

Extended author information available on the last page of the article

\section{Introduction}

Emerging evidence revealed that coronavirus disease 2019 (COVID-19) tends to develop neurological complications, which occur either by the direct impact of novel severe acute respiratory syndrome coronavirus 2 (SARS-CoV-2) on the nervous system or indirectly by immune-mediated para/ post-infection [47]. Direct infection can occur during the acute phase of virus infection, while the second phase may appear even after months following the acute phase [16]. Coronaviruses can invade the nervous tissues involving macrophages, microglia, or astrocytes and can directly damage the nerves [16]. Also, it can induce neurotoxicity via inducing hypoxia-induced injury, imparting immune injury, and binding angiotensin-converting enzyme 2 (ACE2), a cerebrovascular protection factor [16]. Coronaviruses were found to reach the brain predominantly through the olfactory tract during an early stage of infection; however, they 
can rarely invade the brain via systemic circulation [171]. The major complications in the direct infection include encephalitis, meningitis, myelitis, and central nervous system (CNS) vasculitis, while post-infections include Guillain-Barré syndrome (GBS) and other immune-manifested CNS and peripheral nervous system (PNS) diseases [47]. It has been reported that almost $20 \%$ of COVID-19-infected patients require ICU admission because of their neurological complications [55]. Moreover, those patients represent a higher risk of mortality [55]. Emerging evidence revealed that COVID-19 can induce neurologic and immunologic complications, which have a severe impact on the pathogenesis of neurodegenerative diseases [135].

The purpose of our article is to discuss the current status of COVID-19 in developing or worsening neurological complications.

\section{Evidence of Neurological Complications in COVID-19 Patients}

Mao and co-workers first revealed a remarkable impact of COVID-19 in developing neurologic complications [109]. In their study between January 16, 2020, and February 19,2020 , they found about $36.4 \%$ of total 214 COVID-19 patients in Wuhan, China, developed neurologic symptoms which include CNS manifestations (headache, dizziness, impaired consciousness, acute cerebrovascular disease, seizure, and ataxia), PNS manifestations (sensory impairments and nerve pain), and skeletal muscular injury (Fig. 1) [109]. Patients with severe SARS-CoV-2 infection are more susceptible to develop neurologic complications [109]. In a retrospective study in Wuhan, $5 \%$ of a total of 221 patients were found to develop acute ischemic stroke [62]. In another retrospective study in Tongji Hospital in Wuhan, China, 20\% of 113 COVID-19 patients were diagnosed with hypoxic encephalopathy [33]. The first nationwide, cross-specialty surveillance study on acute neurological and psychiatric complications in COVID-19 has been conducted in the UK with 125 COVID-19 patients (median age 71 years) with complete clinical datasets [165]. In this study, $62 \%$ of patients were diagnosed with cerebrovascular events, of whom $74 \%$ presented ischemic stroke, $23 \%$ had unspecified encephalopathy, and $1 \%$ had CNS vasculitis [165]. Among 125 patients, $31 \%$ possessed an altered mental status, comprising $18 \%$ with encephalitis and $12 \%$ with intracerebral hemorrhage [165]. The remaining 59\% satisfied the clinical case definitions for the psychiatric diagnoses, of whom $43 \%$ had new-onset psychosis, $26 \%$ had a neurocognitive syndrome, and $17 \%$ had an affective disorder [165].

Expectedly, the majority (82\%) of the COVID-19 patients with cerebrovascular events were older than 60 years. The incidence of thrombotic complications was found to be significantly high (31\%) in a study comprising 184 ICU patients with SARS-CoV-2 infection in three Dutch hospitals, of whom 23 patients died [85]. In a meta-analysis comprising 1558 COVID-19 patients of the total 6 studies, cerebrovascular disease has been documented as a potential risk factor [167]. In another report, neurological manifestation has been counted as a major risk factor in hospitalized COVID-19 patients in Chicago, USA [97]. Among the studied patients (509), neurological manifestation was present at COVID-19 onset (in $42.2 \%$ patients), at hospitalization (in $62.7 \%$ patients), and at any stage of disease (in $82.3 \%$ of patients) [97]. The major neurologic manifestations include headaches, myalgias, dizziness, encephalopathy, dysgeusia, and anosmia, of all encephalopathy, are associated with a poorer functional outcome in hospitalized patients, independent of COVID-19 severity [97]. A similar observation has been mentioned by the Spanish investigators who documented that neurologic manifestations are common in hospitalized COVID-19 patients in Spain in their study comprising 841 patients [145].

In a systematic review of a total of 67 studies, Montalvan and co-workers proposed that encephalitis, demyelination, neuropathy, and stroke have been associated with COVID-19 [116]. Invasion through the lamina cribrosa and/or olfactory tract and distribution through the trans-synaptic transfer are some of the proposed routes of infection to nerve tissue [116]. An increased risk of secondary neurologic complications in hospitalized COVID-19 patients has been documented in retrospective studies [66]. In a report in the New York Times on October 5, 2020, it was claimed that around 1/3 of COVID-19 patients had altered mental state [17].

\section{Routes and Mechanism of Invasion to CNS}

Emerging evidence revealed that SARS-CoV-2 is a neurotropic, neuroinvasive, and neurovirulent virus to both humans and animals [96]. Human coronaviruses are capable to infect primary cultures of human neural cells, astrocytes, microglia, and oligodendrocytes [96]. SARS-CoV-2 can bind to ACE-2 with higher affinity in its receptor-binding domain (RBD) of the $\mathrm{S}$ spike protein, wherein heparan sulfate functions as a necessary cofactor for their binding at the host cell membrane [76]. ACE2 receptor exists in all human organs including CNS and the endothelial cells. SARSCoV-2 interacts with the ACE2 receptor to invade into CNS via different routes (Fig. 2).

\section{Hematogenous Route}

Coronaviruses can disrupt the epithelial barrier to invade the bloodstream. Alveolar epithelial cells (type II) highly express ACE 2 are predominantly infected by SARS-CoV-2 
Fig. 1 Different neurologic manifestations in COVID-19 patients

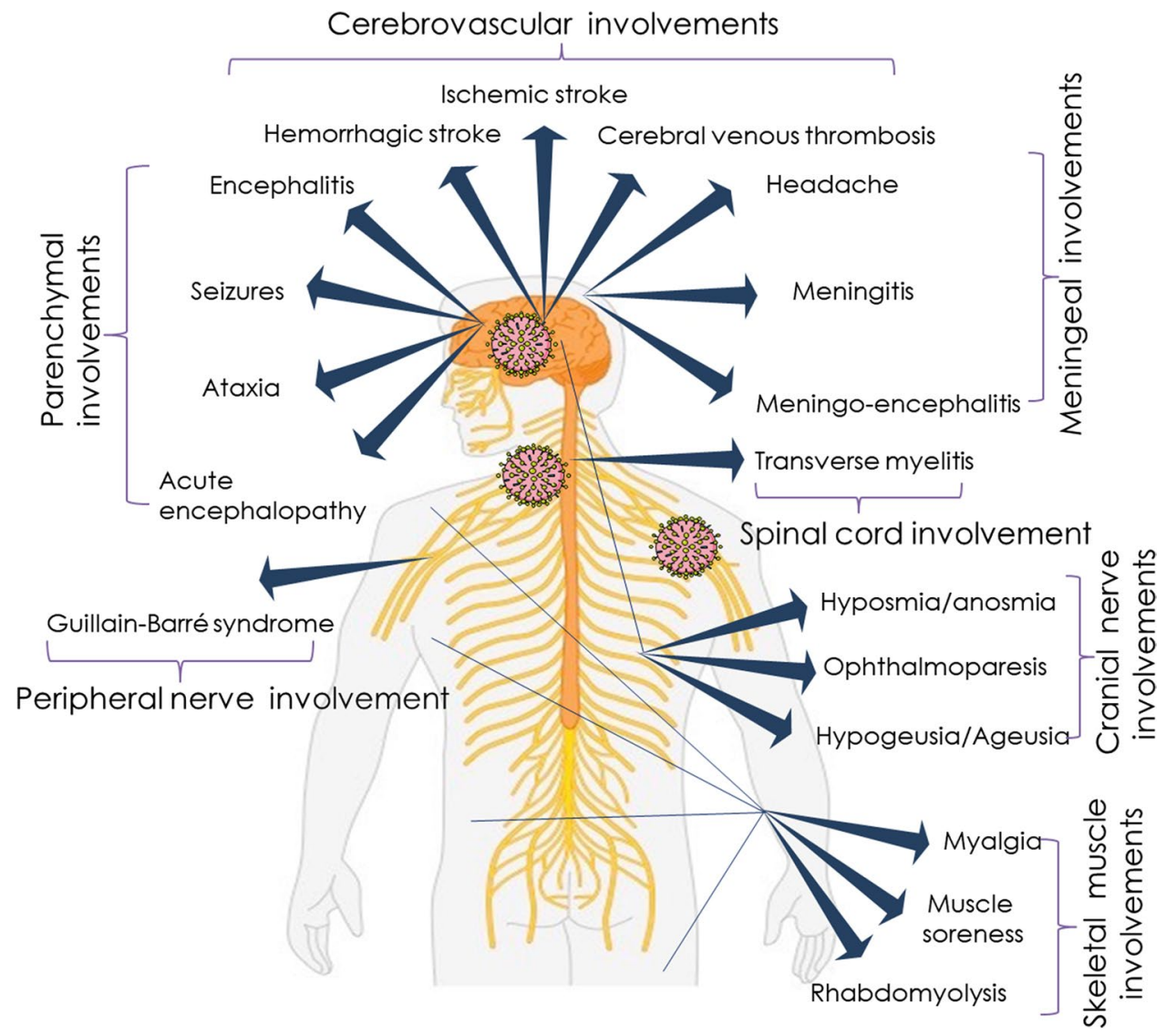

[96]. SARS-CoV-2 can also enter the bloodstream through the epithelial cells of the gastrointestinal tract which is also abundantly expressing ACE2 [90]. Once in the systemic circulation, SARS-CoV-2 can disrupt the endothelial barrier of the blood-brain-barrier (BBB) or the blood-cerebrospinal fluid barrier (BCSFB) via binding to the ACE2 receptors in the endothelial cells and disseminate toward the CNS [90]. SARS-CoV-2-like particles were found in the neural and the capillary endothelial cells in the frontal lobe tissue of a patient who died with COVID-19, which strongly supports the hematogenous-endothelial route of neuroinvasion by SARS-CoV-2 [131]. Also, SARS-CoV-2 can cross BBB by inducing inflammation or hypoxemia through the release of pro-inflammatory chemokines and cytokines [96]. Tumor necrosis factor-alpha (TNF- $\alpha$ ), interferon-gamma (IFN- $\gamma$ ), interleukin (IL)-2, IL-6, and IL-8 have been identified as major pro-inflammatory mediators involved in the cellular invasion of SARS-CoV-2 [3].

\section{Neuronal Route}

In this process, the virus first enters the nerve terminal, where it replicates and is then transported to the soma to invade the CNS [95]. The olfactory tract-mediated neuroinvasion is an important route in the neuronal pathway for respiratory viruses [114]. Also, the virus can invade through other peripheral nerves namely trigeminal and vagus nerves, which innervate different parts of the respiratory tract [175]. Neuroinvasion of SARS-CoV-2 can occur at the neural-mucosal interface via transmucosal entry through the nervous structures followed by their transport by the olfactory tract of the CNS [114]. Some coronaviruses were found to invade CNS through the synapse-connected route via infecting the peripheral nerve endings $[46,96]$. SARS-CoV-2 can invade the neuron via binding with the ACE2 receptor of neurons through the $\mathrm{S} 1$ unit of $\mathrm{S}$ protein executing serine protease transmembrane protease, serine 2 (TMPRSS2) that allows priming [68]. Then, the virus may passively diffuse and/or actively transported through axonal transport via axoplasmic flow as claimed by Dubé and co-workers in their study with human coronavirus (HCoV OC43) [46]. SARS-CoV-2 may also find a path to enter CNS via the trigeminal nerves which innervates nociceptor cells in the nasal fossa. The sensory ending of the trigeminal nerve can exist in the conjunctiva [96]. Recently, a SARS-CoV-2 RNA fragment was found in the ocular discharge of a patient with conjunctivitis [178], which may support the trigeminal nerve-mediated transport of SARS-CoV-2 to CNS. 


\section{Lymphatic Tissue or Cerebrospinal Fluid (CSF) Route}

The lymphatic network is quite abundant in the bronchus and trachea. Nasal lymphatic tissue and the olfactory nerve perineural spaces facilitate the drainage of CSF, which can communicate by the channels made up of ensheathing cells. Lymphatic endothelial cells were found to express the CD209L receptor, which is another receptor for coronavirus invasion [90]. Interestingly, COVID-19 nucleocapsid protein was observed in the cells of lymphoid organs [33]. Thus, it can be speculating that CNS invasion by SARS-CoV-2 indirectly makes through the perivascular or lymphatic path as an indirect route [176].

\section{Infiltration Through Infected Immune Cells}

Coronaviruses can enter to the CNS via infected immune cells, such as T cells, monocytes, and neutrophils, which simultaneously serve as the reservoirs for the virus particles [69]. Immune cells were found to express the binding receptors of coronaviruses [96]. Although no such direct evidence is available regarding the SARS-CoV-2 infection to the immune cells, immunoreactivity of SARS-CoV-2 nucleocapsid protein was observed in CD169+ cells in the splenic marginal zone and marginal sinuses of lymph nodes [33]. In addition, CD169+ cells in the lymphoid system were also found to express ACE-2, which is the
Fig. 2 SARS-CoV-2 infection routes and mechanism of CNS invasion in COVID-19. ACE2, angiotensin-converting enzyme 2 ; CNS, the central nervous system; IFN- $\gamma$, interferon-gamma; $\mathrm{IL}$, interleukin; TNF- $\alpha$, tumor necrosis factor-alpha

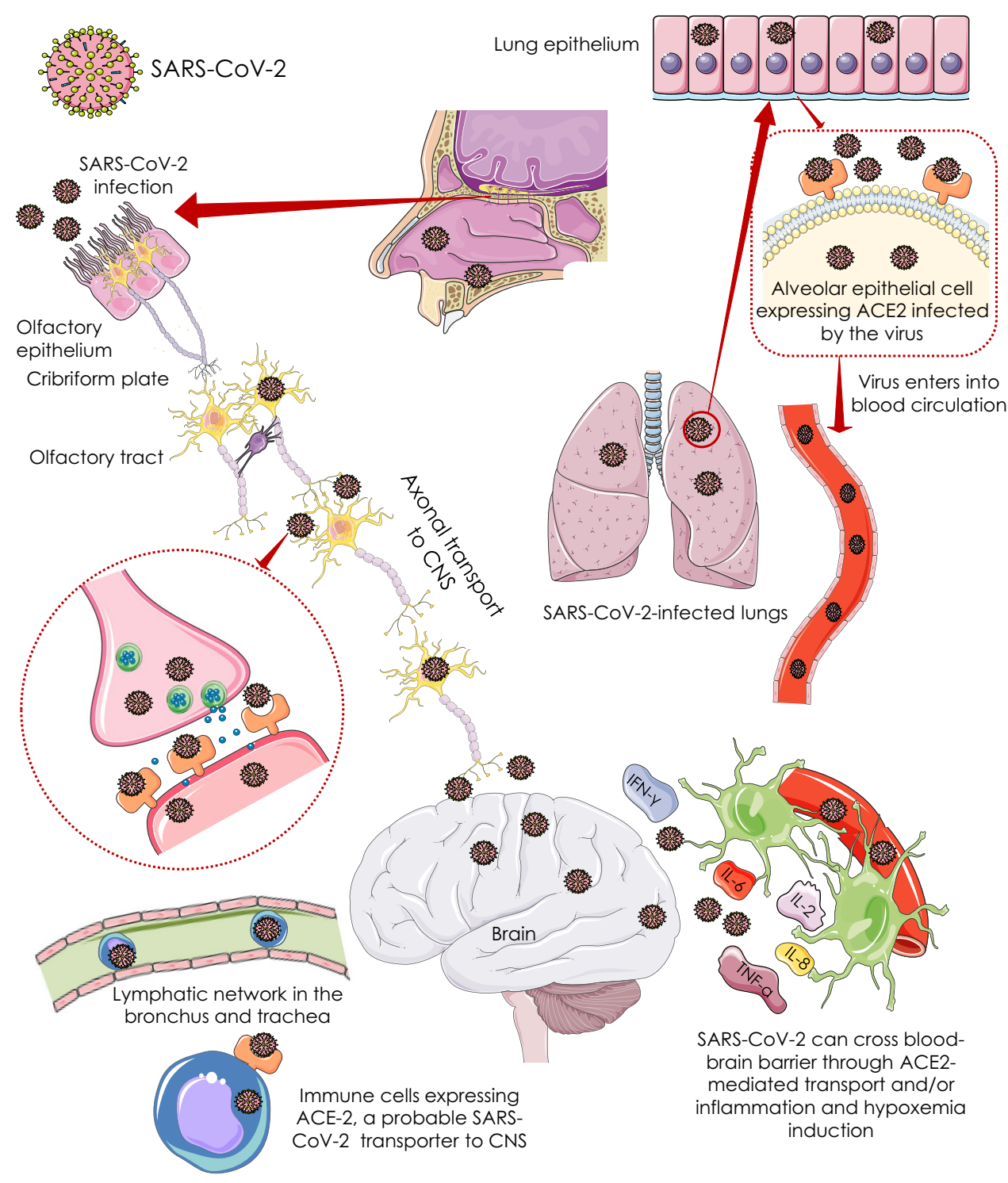


SARS-CoV-2-binding receptor [133]. These observations support that CD169+macrophages may contribute to the spreading of COVID-19. Moreover, the viral RNA sequence has been detected in the macrophages in the broncho-alveolar lavage of COVID-19 patients [20]. Thus, it may not be irrelevant to hypothesize that SARS-CoV-2 can use immune circulating cells to disseminate and invade the CNS.

\section{COVID-19 in Developing Neurologic Manifestations}

Emerging evidence revealed that SARS-CoV-2 infection can attribute to the quite high risk of neurological complications. It can manifest both CNS and PNS complications. These complications are mostly accompanied by the acute innate immune-inflammatory response, higher levels of C-reactive protein, ferritin, and D-dimer [120]. The activation of acute innate immune response results in the release of pro-inflammatory mediators. TNF $\alpha$, IL-1 $\beta$, IL-6, and IL-17 are the key effector cytokines, which increase BBB permeability via microglial activation and proliferation (Fig. 3). BBB breakdown can endorse the pathogenic crosstalk between brain innate and peripheral adaptive immunity thus creating a self-propagating neuroinflammatory microenvironment, which negatively influences neurotransmission and causes glutamate-mediated neuronal toxicity (Fig. 3) [120].

Microglial activation and proliferation can further trigger matrix metalloproteinases (MMPs) which are inducible proinflammatory molecules and can endorse oxidative stress (Fig. 3) [120]. They can simultaneously damage neurovascular endothelium and impair vasodilation resulting in cerebral hypoperfusion (Fig. 3) [120]. In addition, activation of pro-inflammatory mediators, maladaptive immune response, and extensive tissue damage can endorse coagulation pathways. Antiphospholipid antibodies, such as anticardiolipin and anti- $\beta 2$-glycoprotein I antibodies, have been regarded as potential contributors to coagulopathy [179]. Th17 cells and IL-17-mediated activation of the immune responses have been revealed in COVID-19 [170]. IL-17 can induce monocyte chemoattractant protein-1 (MCP-1) and chemokine (C-X-C motif) ligand 1 expression in neurovascular endothelial cells, resulting in trans-endothelial migration of Th17 cells to the brain parenchyma [169]. TNF- $\alpha$ triggers Th17 cell adhesion in the cerebral endothelium through endothelial vascular cell adhesion molecule 1 (VCAM-1) activation [169]. IL-17 can further trigger the activation of pro-inflammatory mediators, such as cytokines, chemokines, and molecules [120]. IL-17 with other cytokines, such as TNF $\alpha$ and IL-1 $\beta$ can activate IL- 6 activity, which, in turn, promotes T cell apoptosis and induces lymphocytopenia in COVID-19 patients [27]. However, evidence also exists that the virus can invade the nerve cells to exert direct pathogenesis [6].
SARS-CoV-2 directly infect the neurovascular endothelia through interaction between viral surface spike-glycoprotein (S1) and ACE2 receptor of endothelial cells, thus induces endotheliopathy, endotheliitis, and vascular injury which may decrease in cerebral perfusion (Fig. 3) [65]. A similar pathogenic mechanism was observed in the peripheral vasculature (Fig. 3). SARS-CoV-2 infection of the brain can also suppress ACE2 expression and activate tissue angiotensin II levels, which may contribute to neuronal dysfunction and neuroendothelial dysfunction (Fig. 3) [74] In addition, the trans-endothelial migration of COVID-19-infected CD169 + macrophages expressing ACE2 can contribute to viral invasion to the brain (Fig. 3). Pavel and co-workers hypothesized that $\alpha$-synuclein accumulation following SARS-CoV-2 infection may intensify pre-existing cell-autonomous susceptibility, which triggers the propagation of $\alpha$-synuclein resulting in neurodegeneration [135]. SARS-CoV-2 protein, such as SRF8, can bind with human protein trafficking molecules; thus, it can negatively regulate the clearance of $\alpha$-synuclein [135]. Also, the neuroinvasion of SARS-CoV-2 can induce bioenergetic stress to certain neural population, such as nigrostriatal dopaminergic neurons, which requires high energy for survival [135]. SARS-CoV-2 infection can trigger the degradation of these susceptible neurons above the threshold of neurodegeneration.

\section{CNS Manifestations}

SARS-CoV-2 is predominantly an airborne respiratory virus; however, it can also invade the brain. Several reports mentioned that SARS-CoV-2 can localize in the brain and CSF of infected patients [114], suggesting its pathological effect on the CNS. In addition, it can indirectly affect CNS via immune and inflammatory mechanisms. However, major CNS symptoms include headache, dizziness, encephalopathy, acute myelitis, cerebrovascular accident, and encephalitis [6]. Headache and dizziness are the most common CNS manifestations in COVID-19 patients followed by encephalopathy [6].

Among all CNS manifestations, encephalopathy has been mentioned as the major cause of morbidity and mortality in adult and elderly COVID-19 patients, independent of the severity of respiratory complications [97]. Altered sensorium has been regarded to increase the risk of mortality in COVID-19 patients [59]. COVID-19 is known to endorse the inflammatory response, which subsequently induces hypoxic/metabolic changes [59]. This hypoxic/metabolic insult triggers cytokine storm which has been regarded as the key mechanism of developing encephalopathy in COVID-19 patients [59]. Umapathi and co-workers demonstrated three COVID-19 patients who developed severe encephalopathy during the disease 
Fig. 3 Proposed mechanism by which SARS-CoV-2 intercedes neurologic manifestations in COVID-19. 3HK, 3-hydroxykynurenine; 5HT, 5-hydroxytryptamine; ACE2, angiotensin-converting enzyme 2; ACE-Ang II-AT1, angiotensinconverting enzyme-angiotensin II-angiotensin II subtype I; CCL2, C-C motif chemokine ligand 2; G-CSF, granulocyte colony-stimulating factor; IFN- $\gamma$, interferon-gamma; IL, interleukin; MIP-2, macrophage inflammatory protein 2 ; NK, natural killer; TNF- $\alpha$, tumor necrosis factor-alpha, indicates downstream pathway; $\uparrow$ indicates upregulation; $\downarrow$ indicates downregulation

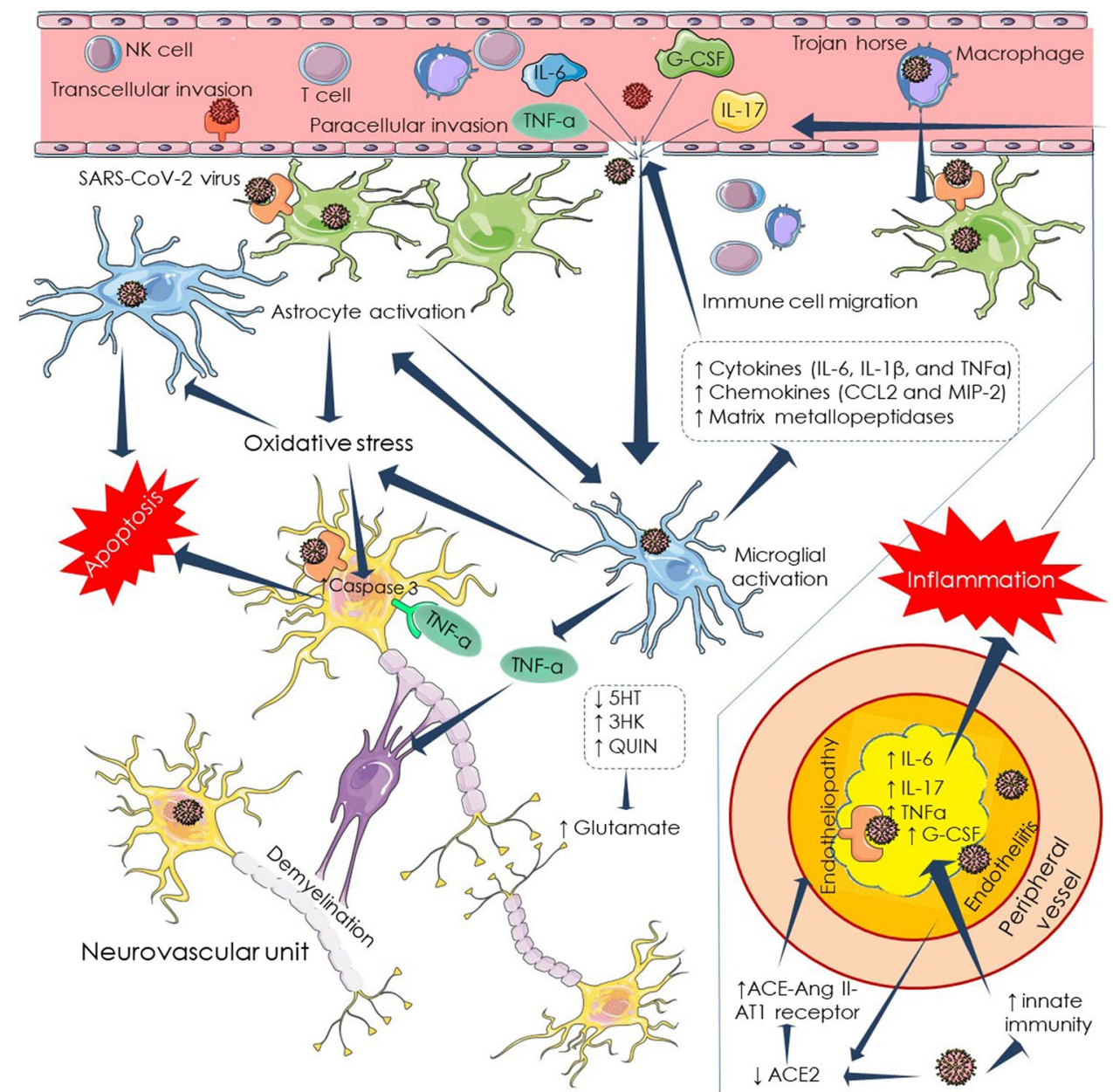

period, and a patient died after 3 months [163]. Several other reports revealed that encephalopathy is one of the common CNS manifestations in COVID-19 patients [8]. Emerging evidence revealed that SARS-CoV-2 can also develop acute hemorrhagic necrotizing encephalopathy [41]. However, COVID-19-manifested encephalopathy does not restrict to elderly patients. In a case report, Kinikar and colleagues reported a case of COVID-19-provoked acute encephalopathy in an 11-year-old child who exhibited altered sensorium and seizures [83]. Other reports also claimed the occurrence of acute encephalopathy in COVID-19-positive children [34, 111]. Altered consciousness, confusion, delirium, and deep coma are the hallmark of clinical features in COVID-19-manifested encephalopathy [59]. Imaging features included leukoencephalopathy, restricted diffusion of both gray and white matters, microhemorrhages, and leptomeningitis [81].

Emerging evidence revealed that encephalitis is another CNS manifestation in COVID-19 patients of different age groups [19]. The SARS-CoV-2-specific RNA has been detected in the CSF of the patient encephalitis-associated with COVID-19, which supported the direct pathogenic role of the virus in developing encephalitis [117]. In a case study, Zuhorn and co-workers revealed that encephalitis in COVID-19 can also be parainfectious without involving the inflammatory pathogenesis having a strong resemblance to the autoimmune encephalitic syndrome [186]. In a multicenter-based study carried out in Italy, 25 out of 45 cases were encephalitis-positive for SARS-CoV-2 infection; however, SARS-CoV-2-specific RNA was not detected in CSF [136]. Delirium, aphasia/dysarthria, and seizures were early clinical symptoms in COVID-19-manifested encephalitis [136]. The treatment of COVID-19-endorsed encephalitis is mainly supportive, and the clinical success was limited [64].

Zhao and co-workers first reported a case of post-infectious acute myelitis in a SARS-CoV-2-infected patient [181]. Emerging evidence revealed that SARS-CoV-2 infection often develops acute transverse myelitis in the patients [152]. The cases of myelitis were mostly seen in elderly patients ( $>60$ years). However, few cases of acute myelitis were also seen in COVID-19-positive middle-aged people [2], an adolescent [63], and a child [79]. Most of the cases were found 
to be post- or para-infectious. The virus-provoked inflammatory manifestations have been regarded as the possible mechanism of myelin damage in the spinal cord [164].

Several cases of cerebrovascular diseases in SARSCoV-2-infected patients have been found [144]. It is more prevalent in severely infected patients having pre-existing vascular risk [122]. Cerebrovascular events have been commonly found in older patients with concurrent stroke as a potential risk factor [11]. $\mathrm{Li}$ and co-workers found that the incidence of stroke in COVID-19 patients was about 5\% in older patients with a median age of 71.6 years [94]. However, COVID-19-related stroke in young patients has also been supported by the data obtained from different centers worldwide [53]. Viral neurotropism, endothelial dysfunction, inflammation, hypoxemia, immunopathogenic, and coagulopathy are plausible anticipated pathophysiologies of cerebrovascular diseases in COVID-19 patients [144]. Inflammation has been implicated in developing cerebrovascular diseases in COVID-19 patients by inducing acute intravascular events mediated through the disruption of the blood supply [11].

\section{PNS Manifestations}

PNS manifestations by COVID-19 are comparatively less severe, which include chemosensory dysfunctions, muscle pain, and GBS [124]. Hyposmia/anosmia and hypogeusia/ageusia are the most frequent chemosensory dysfunctions seen in SARS-CoV-2-infected patients accounting for 5-98\%, depending on the study, methodology, and country [59]. These olfactory and gustatory disorders were mostly reported in asymptomatic individuals or as the initial stage of SARS-CoV-2 infection with no other symptoms [58]. Hyposmia/anosmia and hypogeusia/ageusia were usually observed in mild-moderate cases of SARS-CoV-2 infection; however, hyposmia/anosmia is more intense than hypogeusia/ageusia [59]. The Iranian, European, and US data concluded that $64.5 \%$ and $54.0 \%$ of COVID-19 patients represent smell and taste dysfunctions earlier than the common disease symptoms, respectively [150].

In a study, 60 COVID-19-positive patients in Masih Daneshvari Hospital, Iran, were subjected to a University of Pennsylvania smell identification test, where $98 \%$ of patients exhibited smell dysfunction. The patients were categorized as anosmic (25\%), severely microsmic (33\%), moderately microsmic (27\%), mild microsmic (13\%), and normosmic (2\%) [115]. In another study, Yan and co-workers included 262 ambulatory individuals with influenza-like symptoms; among them, 59 were diagnosed with COVID19 [174]. They found that SARS-CoV-2-infected patients are more susceptible to hyposmia/anosmia (68\% vs. $16 \%)$ and hypogeusia/ageusia ( $71 \%$ vs. $17 \%$ ) as compared to COVID-19-negative patients [174]. Beltrán-Corbellini and co-workers documented a similar observation, where they found that smell and taste disorders were more frequent in COVID-19 patients than in influenza patients [18]. Several studies conducted by different groups around the world also described the loss of chemosensory traits; predominantly, smell and taste dysfunctions are the prevalent symptoms in COVID-19 patients $[5,88]$. Several hypotheses have been proposed to explain the mechanism of anosmia associated with COVID-19. Few reports claimed that SARS-CoV-2 can disrupt the integrity of the olfactory neuroepithelium during olfactory tract-mediated neuroinvasion to CNS resulting in anosmia [115], while others proposed that SARSCoV-2-induced inflammation to the olfactory nerves is the reason behind anosmia in COVID-positive patients [101]. Several hypotheses have also been proposed to explain the mechanism of ageusia during SARS-CoV-2 infection [12]. It has been hypothesized that SARS-CoV-2 can bind to ACE2 receptors lined in the oral mucosa and triggers inflammatory response resulting in cellular and genetic changes, which could alter taste [104]. In a transcriptomic analysis, Xu and co-workers revealed that the lingual expression of ACE2 is higher than in the gingiva or cheek [173]. Thus, it might be the reason for hypogeusia/ageusia during SARS-CoV-2 infection. In contrast, Moein and co-workers proposed that traumatic injury to the olfactory system is the main reason behind the hypogeusia/ageusia in COVID-19 patients [115].

GBS is one of the frequently manifested PNS complications in SARS-CoV-2 infection. Zhao and coworkers reported the first case of GBS in a 61-year-old COVID19-positive woman [180]. After this, several cases of GBS in COVID-19 patients have been documented around the world $[9,23]$. The clinically presenting features of GBS in COVID19 patients included acute symmetric flaccid, quadriparesis, facial paralysis, lower-limb weakness, ataxia, paresthesia, and distal weakness [9]. The mechanism of developing GBS in COVID-19 patients has not been revealed yet; however, it has been thought that autoimmune or direct neurotoxic effects of the virus might cause GBS in COVID-19 patients [121]. Recently, Lucchese and Flöel revealed that molecular mimicry between the virus and human heat shock proteins (HSPs), such as HSP90 and 60, can attribute to the pathogenic mechanism of GBS following SARS-CoV-2 infection [105]. HSPs might also endorse a superantigen response, which can contribute to the para-infectious response [89]. Treatment with immunoglobulins or plasmapheresis was found to ensure partial or complete recovery; however, some patients required ventilation support [140].

Few cases of cranial neuropathies have been reported to be associated with COVID-19 pneumonia. Wei et al. first described a case of acute oculomotor nerve palsy in a 62-year-old severely ill patient [168]. Few cases of abducens nerve palsy have been recorded in SARS-CoV-2-infected patients presenting ophthalmoparesis [45]. In a study, Srijon 
and coworkers found 6 cases of abducens nerve palsy out of 19 COVID-19-positive patients in Bangladesh [156]. Few cases of facial nerve palsy have also been found in COVID19-positive patients [43]. Virus-mediated immune-inflammatory response has been proposed to be a possible mechanism in cranial neuropathies [168].

\section{Skeletal Muscle Manifestations}

Emerging evidence revealed that muscle pain (myalgia), muscle soreness, and fatigue are frequently encountered symptoms in COVID-19 patients. Mao and coworker first mentioned the incidences of muscle injury of $19.3 \%$ and $4.8 \%$ in severely and moderately ill COVID-19 patients, respectively [109]. Lippi et al. reported that myalgia can be the onset symptom in 36\% of COVID-19 patients [98]. In a meta-analysis comprising 38 studies involving 3062 COVID-19 patients, Zhu and co-workers found that 33\% of the COVID-19 patients exhibited muscle soreness [184]. In another meta-analysis, Cao and colleagues reported that $35.5 \%$ of a total of 46,959 COVID-19 patients (in 31 studies) developed muscle soreness and fatigue [28].

Rhabdomyolysis characterized by myalgia, fatigue, and hemoglobinuria has been described as a life-threatening syndrome in COVID-19 patients [161]. It has been ascribed as an early-late manifestation in COVID-19, which can lead to acute renal injury $[113,161]$. Several hypotheses exist regarding the pathogenic mechanism of muscle manifestations in COVID-19 patients. In addition to the common inflammatory mechanism caused by viruses, hyperlactatemia caused by a hypoxic condition in the tissue during SARS$\mathrm{CoV}-2$ infection has been proposed as a key mechanism in COVID-19-induced muscle injury [39]. Hyperlactatemia further suppresses the oxygen-carrying capacity of red blood corpuscles, which further intensifies hypoxic conditions in the muscle tissues [87]. In addition, SARS-CoV-2 can directly infect the musculoskeletal system expressing endothelial cells of the skeletal muscle and spinal cord through ACE2, which have been also regarded as the mechanism of musculoskeletal manifestation in COVID-19 patients [157]. Analgesics may not be therapeutically effective in attenuating such pain; however, viral exclusion has been proposed to be a potential therapeutic strategy [87].

\section{COVID-19 in Pre-existing Neurological Diseases}

\section{COVID-19 in Alzheimer's Disease}

It has been found that both SARS-CoV-2 infection and Alzheimer's disease $(\mathrm{AD})$ predominantly affect the elderly population. $\mathrm{AD}$ is a notable neurodegenerative ailment, while COVID-19 was also found to induce several neurotoxicological manifestations. Thus, there must be some crosstalks in the pathogenesis of AD and COVID-19 pneumonia. In general, the mortality rate from pneumonia is almost two-fold in people with dementia contrasted with those without dementia [91]. Emerging evidence revealed that the presence of $\mathrm{AD}$ is a potential risk factor for COVID-19 severity [10]. Immune response and intense inflammation in SARS-CoV-2 infection may accelerate the neurodegeneration in the CNS, which may endorse a high risk of neuropathological consequences [123]. Emerging evidence suggests that amyloid fibrils can induce microglial activation and triggers type 1 interferon response, which is also a crucial component in SARS-CoV-2 infection (Fig. 4) [147]. Thus, pre-existing AD might exacerbate the pathological occurrences with SARS-CoV-2 infection via creating a "perfect storm" of an intense immune response (Fig. 4) [123]. Moreover, the risk of SARS-CoV-2 infection accounts higher in patients with AD [183].

In a UK Biobank study, Yu and coworkers indicated that AD patients are in expanded danger of SARS-CoV-2 infection. In their study, they showed that $\mathrm{AD}$ is one of the potential comorbid factors linked to COVID-19-related mortality [177]. Recent studies explored a higher ACE2 expression in the brain of AD patients, which can facilitate viral load in the brain and thus intensify the risk of COVID-19-related mortality in AD patients (Fig. 4) [141]. In contrast, Kehoe et al. reported that brain ACE2 activity is reduced in $\mathrm{AD}$, which results in the resilience of AD to COVID-19 as reported in a retrospective analysis [80]. In a recent report, it has been revealed that Alzheimer's gene is linked to the risk and severity of SARS-CoV-2 infection. The APOE $\varepsilon 4$ gene variant that possesses the greater risk of developing $\mathrm{AD}$ also confers a risk allele in severe COVID-19 [70]. Considering the vulnerability of AD patients to COVID-19, it may be postulated that the isolation of AD patients is necessary to avoid SARS-CoV-2 infection. However, isolation negatively affects $\mathrm{AD}$ patients as it increases the risk of cognitive decline due to a lack of social interaction [123]. In a survey, Canevelli and colleagues reported that $31 \%$ of dementia patients developed significant cognitive decline during the first month of lockdown, while 54\% exhibited deterioration in agitation, depression, and apathy [26]. Thus, the preventive strategy about both pharmacological and non-pharmacological interventions would aid in this perspective [1].

\section{COVID-19 in Parkinson's Disease}

Parkinson's disease (PD) is the second most common neurodegenerative disease characterized by a large number of motor and non-motor symptoms. Emerging evidence revealed that PD patients may be at an elevated risk of severe complications following SARS-CoV-2 infection [149]. Researchers at the University of Iowa Health Care reported that people with PD are at a $30 \%$ higher risk of COVID19-related deaths [178]. According to their observation, 
148 (21.3\%) out of 694 COVID-19 patients with PD died, compared to 4290 (5.5\%) out of 78,355 COVID-19 patients without PD died [178]. In search of the mechanistic aspect, it has been hypothesized that COVID-19 is known to trigger neuroinflammation, which can subsequently trigger $\alpha$-synuclein accumulation resulting in neurodegradation, which is similar to that of PD pathogenesis (Fig. 4). Following neuroinvasion, SARS-CoV-2 has been proposed to endorse the activation of microglia and astrocytes, which subsequently trigger inflammation, oxidative stress, and glutamate favoring neurodegradation (Fig. 4).

Increased accumulation of $\alpha$-synuclein can trigger microglial activation, which can subsequently endorse astrocyte activation via TNF- $\alpha$ resulting in increased glutamate release (Fig. 4). Cerebral $\alpha$-synuclein accumulation, inflammation, and oxidative stress are the key factors in PD pathogenesis, which are endorsed by COVID-19. In an experimental model, PD in rats exhibited TMPRSS2 upregulation in the brain [92], which is a receptor for SARS-CoV-2 for tissue invasion, thereby PD condition may facilitate neuroinvasion of the virus (Fig. 4). In addition, SARS-CoV-2 neuroinvasion induces bioenergetic stress resulting in the neurodegeneration of certain neural cells which require large energy for functioning [135]. Nigrostriatal dopaminergic neurons require high cellular energy requirements, thus vulnerable to SARS-CoV-2 infection [135]. Thus, at least theoretically, there may be neurobiochemical crosstalk exists between COVID-19 and PD.

Recently, Chaudhry et al. reported that SARS-CoV-2 infection in 6-hydroxydopamine-treated dopamine-containing neurons caused activation of caspase cascade via $\mathrm{NF}-\mathrm{KB}$ signaling resulting in the death of dopaminergic neurons [32]. Activation of NF- $\mathrm{kB}$ signaling could impart neurodegenerative effects through pro-apoptotic and proinflammatory mechanisms (Fig. 4), wherein a regulatory role of $\beta$-catenin or its-activating signaling over NF- $\kappa B$ and
Fig. 4 Proposed mechanism by which SARS-CoV-2 infection in COVID-19 worsens AD and PD. IFN, interferon; IL, interleukin; MCP-1, monocyte chemoattractant protein-1; NF- $\kappa \mathrm{B}$, nuclear factor kappa-lightchain-enhancer of activated B cells; TGF- $\beta$, transforming growth factor-beta; TNF- $\alpha$, tumor necrosis factor-alpha

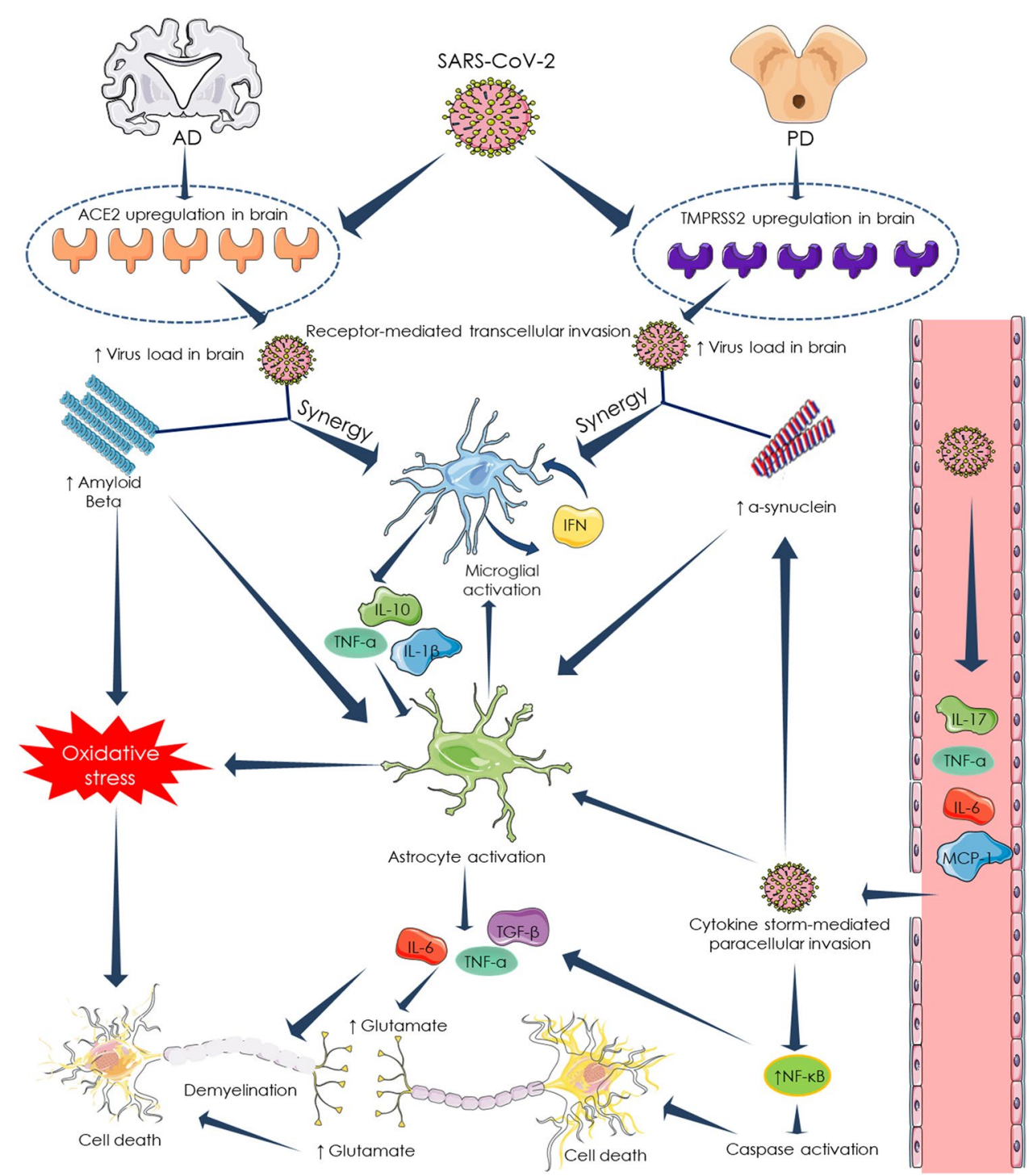


inflammatory cytokine function could be of therapeutic significance [75]. In contrast, Prasad and colleagues found that only $10 \%$ out of 100 COVID-19-positive PD patients in India worsened PD severity or developed new symptoms [138]. Similarly, Artusi and coworkers concluded that COVID-19 risk and mortality did not vary between PD patients and the general population [14]. A similar finding was reported in another survey on mild-moderate PD patients in Lombardy, Italy, where COVID-19 risk and death did not differ from the control; however, symptoms seemed to be milder [50]. On the other hand, In a UK Biobank study, Yu and coworkers reported that $\mathrm{PD}$ can be associated with an elevated risk of SARS-CoV-2 infection; however, unlike AD, it does not have a significant impact on the mortality rate [177]. On the other hand, Fasano and coworker found that the mortality rate of $19.7 \%$ among community-dwelling PD patients following SARS-CoV-2 infection is a significantly high percentage [50]. However, older PD patients ( $>78$ years) are more vulnerable to COVID-19 death compared to younger patients [13]. In another study in Italy, PD patients exhibited substantial deterioration in motor and non-motor symptoms during mild-moderate SARS-CoV-2 infection as compared to COVID-19-negative PD patients [35]. Emerging evidence revealed that SARS-CoV-2 infection often develops parkinsonism [4]. Several hypotheses have been proposed in this regard. SARS-CoV-2 can induce nigrostriatal damage via inducing vascular insult to the brain by ACE-2 binding, triggering neuroinflammation in the brain, and aggravating intraneuronal $\alpha$-synuclein accumulation [21]. Though the possibilities are theoretical and speculative, however, the existing evidence regarding the involvement of other viruses in PD pathogenesis and the neuroinvasive capacity of COVID-19 supports the hypotheses.

\section{COVID-19 in Multiple Sclerosis}

Multiple sclerosis (MS) is an immune-manifested, chronic immune-mediated, and neurodegenerative disorder, which requires immunosuppressive medication as a therapeutic option. Thus, MS patients may face additional challenges in this COVID-19 pandemic situation [185]. Mansoor and colleagues claimed that disease-modifying therapy (DMT) involving immunosuppressants might yield a higher risk of acquiring infection or yield poorer outcomes [108]. Additionally, MS is a neurodegenerative disease; thus, it may be expected that a neurotropic virus-like SARS-CoV-2 would have some effect on disease manifestation and/or exacerbation [148]. Palao and coworkers reported that a patient develops MS following SARS-CoV-2 infection [130]. The virus-provoked inflammation of the optic nerve and demyelination in the CNS nerves play crucial a role in the clinical onset of MS [130]. Crescenzo and co-workers found that the prevalence of COVID-19 seemed to be almost 2.5-fold in MS patients than in the general population [38]. In an MS cohort comprising 40 patients, Chaudhry and coworkers found that COVID-19 can be a risk factor to MS patients only in case of severe infection. However, most of the severely infected patients were found older [31]. Since the study comprised only a limited number of patients in each category, it is difficult to obtain a countable conclusion. However, their observation is not supportive of that of the majority of available literature. Mansoor and Ghasemi-Kasman revealed that DMT does not trigger SARS-CoV-2 infection in MS patients by suppressing immune and cytokine responses [146].

In a cohort of MS patients in the Netherlands, Loonstra and colleagues concluded that DMT does not have any impact on COVID-19 outcomes [100]. Similarly, others also concluded that DMT does not increase the risk of contracting COVID-19 disease in MS patients [48]. Parrotta and coworkers concluded that DMT involving anti-CD20 therapies and sphingosine-1-phosphate receptor modulators to COVID-19-positive MS patients did not increase the risk of hospitalization or mortality [134]. Dalla Costa et al. also reported that DMT did not significantly change the risk and severity of COVID-19; however, a trend of an increased risk toward the infection was observed with immunemodulators, such as alemtuzumab and cladribine [40]. Additionally, MS patients did not exhibit any evidence of worse COVID-19 outcomes [40]. Similarly, others also concluded the protective role of immunosuppressive agents in COVID-19-positive MS patients [126]. Kloc and Ghobrial reported that MS DMT could be protective against acute respiratory distress syndrome in COVID-19 patients [84].

DMT drugs, such as fingolimod and siponimod, can inhibit the expression of ACE2 receptors and can recruit macrophages to the lungs, which can suppress cytokine storm [84]. MS patients who received fingolimod treatment and were infected by COVID-19 exhibited a surprisingly fast recovery [107]. Fingolimod has been proposed to enhance the integrity of lung endothelial cells and attenuate the cytokine storm via immunosuppression [142]. However, following an international consensus statement, fingolimod might be stopped in MS patients diagnosed positive for SARS-CoV-2 infection [107]. Zheng and coworkers reported the safety aspects of the individual medicines used in DMT in the COVID-19 pandemic situation. They concluded that ocrelizumab may be the safest drug if it is used sparingly, while cladribine may be relatively safer than alemtuzumab in the oral form [182]. In this aspect, the effect of DMT for MS on vaccine responses is one of the crucial points as certain treatments may interfere with building a protective immune response upon vaccination [36]. In addition, DMT that affects the adaptive immune system can lessen the efficacy of vaccines by suppressing long-term immune memory development [36]. Ciotti and colleagues claimed that apart from $\beta$-interferons, many DMT drugs can reduce 
the efficacy of several types of vaccines via suppressing humoral immune responses [36]. However, in a case study of 7 SARS-CoV-2-infected MS patients receiving antiCD20 treatment, Meca-Lallana and coworkers revealed that humoral immunity is not always essential for a clinical course of SARS-CoV-2 infection [112]. Baker and colleagues reported that most DMTs do not particularly target the innate immune system. Only a few have a long-term impact on CD8 T cells, and a few can block the immature B cell formation [15]. An interesting finding was found in a population-based MS cohort comprising 1931 patients, in which below $1 \%$ of the high risk of COVID-19 mortality was recorded [22]. Importantly, the majority of these MS patients did not receive any DMT [22]. In another registry-based cohort study of patients with MS, no connotation was found between DMT exposure and COVID-19 severity [102].

\section{COVID-19 in Epilepsy}

As indicated by the Epilepsy Foundation's assertion, epilepsy patients do not pose any additional risk for SARS-CoV-2 infection or worsening of the disease severity (https://www. epilepsy.com/learn/covid-19-and-epilepsy). Epilepsy does not affect the immune system, and antiepileptic drugs do not possess any immunosuppressive properties [185]. In a survey-based study, Fonseca and colleagues reported that SARS-CoV-2 infection does not cause any change in seizure frequency in 5 epilepsy patients [54]. In contrast, CabezudoGarcía et al. reported that patients with active epilepsy are more vulnerable to SARS-CoV-2 infection than the general population [24]. Also, active epilepsy is a potential risk factor accounting for $23 \%$ of mortality in hospitalized COVID-19 patients [24]. Few rare cases with new-onset seizures were also reported in COVID-19 patients [166]. In a retrospective study in Wuhan, China, it has been concluded that the COVID-19 patients with new-onset or recurrent epileptic seizures endorsed severe SARS-CoV-2 infection, which may yield a poor prognosis [158]. Patients with recurrent epileptic seizures exhibited a large number of other neurological manifestations than patients with new-onset epileptic seizures [158]. Treatment with antiepileptic drugs may reduce the risk of recurrent seizures [158]. However, drug interaction can be a crucial factor for COVID-19-positive epilepsy patients. For example, (a) hydroxychloroquine and chloroquine may lower the seizure threshold, (b) hydroxychloroquine and chloroquine are contraindicated in patients receiving lacosamide and cenobamate, and (c) lopinavir/ritonavir, favipiravir, remdesivir, and ribavirin cannot be co-administered with antiepileptic drugs, such as carbamazepine, phenobarbitone, phenytoin, and primidone [132]. In this aspect, an updated list has been provided by the University of Liverpool (https:// www.covid19-druginteractions.org).

\section{COVID-19 in Myasthenia Gravis}

Myasthenia gravis (MG) patients have been regarded to be at the risk of severe SARS-CoV-2 infection [185]. At least theoretically, a disease like MG is associated with respiratory muscle weakness and requires immunomodulation/ immunosuppression as therapeutic management may be at a higher risk of infection and severity of COVID-19 [71]. Several studies and surveys reported that SARS-CoV-2 infection can cause exacerbation of MG symptoms [118, 119]. Muppidi and colleagues reported that $40 \%$ of 91 COVID19-suspected MG patients exhibited MG worsening or crisis in the COVID-19 setting and required rescue therapy with intravenous immunoglobulin, plasma exchange, or steroids. Forty-three percent of patients were recovered or released from the hospital and $24 \%$ of patients died due to COVID19 [119].

In an observational retrospective study involving 15 hospitalized MG adults with severe SARS-CoV-2 infection in São Paulo, Brazil, Camelo-Filho and coworkers reported that $87 \%$ needed intensive care support, $73 \%$ required mechanical ventilation, and 30\% died [25]. A rare case with newonset MG developing secondary to SARS-CoV-2 infection was also reported [143]. Only a few findings reported that COVID-19 did not manifest any new crisis or symptom exacerbation in MG patients [143]. However, the populations in these studies were too low ( $\mathrm{n}=5$ and 1 , respectively) to reveal any conclusive evidence. The treatment options in COVID-19-provoked MG worsening include symptomatic, immunosuppression, and immunomodulation; however, treatment choice is very important in this regard [67]. Immunosuppression has been found to offer better therapeutic outcomes [25]. However, MG patients with SARS-CoV-2 infection often raise several clinical dilemmas, particularly those of immunocompromised subjects [42]. In addition, the side effects of the immunosuppressant may also occur [42]. For example, intravenous immunoglobulin (IVIg) treatment often develops thrombosis in susceptible patients [42]. The selection of COVID-19 medicine is also important in this regard. Some drugs used in therapeutic trials of COVID-19 management, such as hydroxychloroquine and azithromycin, can aggravate symptom exacerbations in MG [71].

\section{Factors Affecting Neurologic Manifestations in COVID-19 Patients}

\section{Age}

It has been revealed that the viral burden is highly associated with advanced age because of the poor immunity as well as the relative abundance of ACE2 receptor expression in the older population than younger people [110]. 
The presence of comorbidities more likely in older people can also endorse severe impacts [110]. In addition, older patients also represent lower extents of human miRNAs that target SARS-CoV-2 [57], thereby enabling the virus to penetrate and replicate more easily within older patients. Therefore, the utility of miRNA-based therapy given its suppressive function warrants further investigative and clinical consideration [93]. It has been found that older patients are more vulnerable in developing neurologic manifestations and worsening the pre-existing neurological ailments following SARS-CoV-2 infection. In the first report regarding the neurological complications in COVID-19 patients, Mao and colleagues found that patients with a mean age of 58.2 years are more prone to severe infection as well as in developing neurological manifestations than younger people [109].

In a UK-wide surveillance study on COVID-19 patients, Varatharaj and colleagues reported that a slightly high percentage of older patients ( $>60$ years) showed altered mental status than the patients below 60 years, while the risk of cerebrovascular events is significantly high in older patients $(82 \%)$ than the patients below 60 years (18\%) [165]. Cerebrovascular events are prevalent in older patients with concurrent stroke as a potential risk factor [47]. However, few cases of younger stroke patients were also reported [99]. Encephalopathy, the most frequent CNS manifestation in COVID-19, has been manifested more likely in older patients (mean age 65.5 years) than the patients with a mean age of 55.2 years [97]. However, in the same study, among the patients, those without or had a long time from COVID-19 onset to hospitalization, the patients with a mean age of 57.5 years were more likely to present any neurologic manifestations than older people (mean age 62.9 years). Garg and colleagues reported that COVID-19-associated encephalopathy most likely occurs in patients over 50 years of age [60]. Acute myelitis, another CNS manifestation in COVID-19 patients, was mostly found in elderly people of 60 years or more [152]. Among the PNS manifestations, hyposmia/anosmia and hypogeusia/ageusia are the most common in COVID-19 patients, which more frequently occur in young adults [52]. Earlier evidence revealed that smell and/or taste dysfunction is more common in the younger COVID-19 patients [125]. Speth and colleagues also reported that smell dysfunction is negatively associated with age [155]. GBS is another PNS manifestation in COVID-19 patients with higher frequency among elderly patients with a mean age of 60 years [162]. In contrast to adult patients, children are less susceptible to develop neurologic manifestations following SARS-CoV-2 infection [82]. The most common neurological manifestations in children include headache and loss of smell and/or taste [82]. However, only a few cases of encephalography, encephalitis, seizure, cerebrovascular infarction, and GBS were also reported to occur in pediatric patients [153].

\section{Sex}

Relatively fewer published documents are available regarding the gender bias of COVID-19 in developing neurological manifestations and worsening pre-existing neurological complications. Compared to men, women are less vulnerable to viral infections due to the differences in innate immunity and the presence of $\mathrm{X}$ chromosomes [37]. $\mathrm{X}$ chromosomeencoded immune regulatory genes result in lower viral load and less inflammation in women than in men [37]. Women additionally produce more antibodies that persist in the circulation for an extended period than men [37]. It has been revealed that sex hormones can additionally modulate ACE-2 expression and immune response [7]. Estrogen (female sex hormone) has been regarded as an immunostimulant, while testosterone (male sex hormone) is an immunosuppressant toward viral infection [137]. Also, testis can harbor SARSCoV-2 due to an abundance of ACE2 expression, and accordingly, males exhibit poor viral clearance [154]. Thus, the male becomes the weaker sex concerning endurance and disease severity. Jin and coworkers reported that men (70.3\%) are at a much higher risk of lethal outcomes than women (29.7\%) independent of their age [73]. Several reports concluded that women are at lower risk of COVID-19 severity than men in different country cohorts [127]. Considering the effect of sex on endurance and disease severity, there may be some gender issues in COVID-19-provoked neuropathological events. Women were found to develop PNS manifestations, mainly olfactory and gustatory dysfunctions, more often than men after SARS-CoV-2 infection. Several reports concluded that women are more vulnerable to developing chemosensory dysfunctions following SARS-CoV-2 infection than men [61]. The subjective neurological complaints, such as hyposmia, dysgeusia, headache, daytime sleepiness, and depression, were more common in COVID-19-positive females than males [59]. However, COVID-19-positive male patients are more likely to develop GBS than females [29]. On the other hand, major CNS manifestation like encephalopathy more frequently affects male patients compared to females [97]. The incidences of COVID-19-manifested cerebrovascular events including strokes are also less frequent in female patients [159]. In a review on "COVID-19 and stroke," Qi and coworkers compared several case studies and surveys, in which a majority of stroke presentation in COVID-19 was found in male patients [139]. Female steroid hormones have been found to exert a neuroprotective role through anti-inflammatory and antioxidative effects, which may be accountable in this regard [106]. 


\section{Comorbidity and Disease Severity}

The presence of comorbidity and severity of SARS-CoV-2 infection has been regarded to trigger lethal outcomes in COVID-19 patients. In a report on neurologic manifestations in COVID-19 patients, Mao and colleagues concluded neurologic manifestations are more common in severely ill patients and/or patients presenting more comorbidities [109]. Neurologic manifestations and complications are more likely to occur in severely ill patients representing more comorbidities, such as hypertension and other vascular complications [59]. In a retrospective observational study in Wuhan, China, comprising 86 patients, Fan and colleagues reported that neuromuscular diseases, delirium, and stroke are common neurologic manifestations in critically ill patients with pre-existing cerebrovascular comorbidity [49]. The incidences of stroke have been implicated in elderly patients presenting numerous vascular comorbidities [160]. In a bicentric French cohort, Helms and coworkers found that delirium or neurological symptoms are major issues in the COVID-19 patients in ICUs [65]. Encephalopathy is a common CNS manifestation in COVID-19 patients with severe infection, cardiovascular comorbidities, multi-organ system dysfunction, and systemic inflammation [78]. Consciousness disorders were frequently seen mostly in patients with severe and advanced SARS-CoV-2 infection [145]. In a multicenter retrospective cohort of 917 COVID-19 patients in 56 Chinese hospitals, neurologic comorbidities have been regarded to be the potential risk factor in developing severe neurologic manifestations, including impaired consciousness and cerebrovascular complications [172].

The presence of comorbidities, such as hypertension, diabetes mellitus, obesity, dyslipidemia, heart disease, and tobacco smoking, and disease severity is the potential risk factors in developing neurologic manifestations in COVID-19 patients in a retrospective single-center cohort of 841 hospitalized patients in Spain [145]. Several other reports revealed that severely ill COVID-19 patients and/ or the patients representing comorbidities are more likely to develop neurologic manifestations [128]. In contrast, chemosensory dysfunctions were recorded in less severe COVID-19 cases [145]. Pre-existing neurodegenerative or neuroimmunological diseases such as AD, PD, and MS have been implicated in further neurodegeneration in COVID-19 patients [51]. PD patients represent substantial worsening of both motor and non-motor (mostly fatigue) symptoms even in mild and moderate COVID-19 disease [13]. COVID-19 may have a potential role in future neurodegeneration in $\mathrm{AD}$ patients via triggering neuroinflammation and subsequent $\beta$-amyloid-induced type I interferon response [123]. AD patients develop a higher risk of cognitive decline after overcoming the primary SARS-CoV-2 infection [51]. Patients with dementia more likely represent atypical COVID-19 symptoms without fever and/or cough, which are primarily neurologic manifestations [72]. Thus, the presence of neurodegenerative diseases can also be regarded as comorbid factors in developing neurologic manifestations in COVID19 patients.

\section{Treatments of COVID-19-Induced Neurological Manifestations}

Until safe and effective medicines or vaccines will arrive, therapeutic management will focus on antiviral agents for attenuating SARS-CoV-2 infection and the management of its outcomes, such as respiratory trouble, immune dysregulation, systemic inflammation, hypercoagulation state, and organ failure [77]. So far, according to the standard protocols, no specific treatment is managed for COVID-19-provoked neurologic manifestations. On the preventive side, several herbal formulations and natural compounds were found to support brain health, and also its homeostatic and nootropic function [86]. Severe systemic disease, hypoxia, hyperinflammation, hypercoagulation, and immune dysregulation are hypothesized to endorse neurologic manifestations in SARS-CoV-2-infected people. Therefore, in most cases of neurological manifestation, these factors were targeted to achieve the therapeutic goal. Thus, therapeutic approaches may include suppression of immune hyperactivation by steroids and modulation of immune dysregulation via targeting cytokines, chemokines, and other inflammatory mediators [69]. Several trial medicines were tested to treat specific neurologic manifestations in COVID-19 patients; however, the disease state, severity, and patient factors largely impacted these trial medicines. Lovell and colleagues proposed that benzodiazepines could be an effective therapeutic option for patients with agitation; however, it could be lethal for patients with respiratory failure and who do not have ventilation support [103].

COVID-19-provoked delirium may be treated following the conventional delirium management strategy; however, hyperactive delirium in COVID-19 patients needs more aggressive management [151]. Persistent encephalopathy is the most critical CNS manifestation in the COVID-19 patients and, so far, remains unresponsive to the majority of attempted treatments. Despite substantial adaptations that have been undertaken on acute stroke management in COVID-19 patients, the conventional strategy for acute stroke treatments, including systemic fibrinolysis and mechanical thrombectomy, was not disregarded in the COVID-19 setting [56]. Typical treatments of acute myelitis generally aim to prevent or minimize the existing neurological deficits [164]. Treatment with corticosteroids and other therapies including plasmapheresis, which suppresses the immune system, can ensure partial recovery. Concomitant 
physical therapy can improve the outcomes [30]. Since there is no specific treatment option for headaches associated with SARS-CoV-2 infection, careful pain management is required. Also, pain in COVID-19 patients can be associated with myalgia and peripheral neuropathies. The lack of nursing and physiotherapy in COVID-19 patients resuscitates using high-dose intravenous opioid infusions for a prolonged period [44]. Peripheral neuropathies in COVID-19 patients may require an addition of gabapentinoids, such as gabapentin and pregabalin for pain management [44]. Treatment of COVID-19-induced GBS is the same as those that followed any other acute inflammatory neuropathy [129]. Immunoglobulin infusions are potentially useful than plasma exchange therapy, particularly for those patients who are still infected. No specific treatment is required for chemosensory dysfunctions in COVID-19 patients as these are self-limiting in the majority of the patients [129]. However, special attention is required on drug-drug interaction, particularly between drugs used for COVID-19 management and drugs used to treat neurological manifestations.

\section{Challenges and Conclusions}

Although COVID-19 principally infects the respiratory tract and causes severe respiratory disorders, several cases of neurologic manifestations have been reported in COVID19 patients. Neurologic manifestations were more common in old and severely ill patients, which potentially increase the risk of mortality in COVID-19 patients. The presence of comorbidities can further deteriorate neurological complications and worsen the clinical outcomes. The exact neurotoxic mechanism of COVID-19 is yet to be explored; however, a large body of clinical and experimental data hypothesized that neuroinvasion, endothelial dysfunction, neuroinflammation, immune-pathogenecity, and hypoxemia may contribute to the development of these CNS manifestations.

Patients with existing neurodegenerative or inflammationmediated neurological diseases may also increase the risk of neurologic manifestations in COVID-19 patients; however, the direct association and post-infective effect have yet to be revealed. The exact pathogenesis of COVID-19 in the manifestation of neurological complications is yet to be revealed. The clinical spectrum and consequences of neurologic manifestations in COVID-19 patients are broad and heterogeneous. The presence of SARS-CoV-2 in the brain has been detected, and several hypotheses of neuroinvasion have been proposed. Thus, the theory of neuroinvasion and the direct effect of the virus on the nervous system may not be excluded; however, the absence of virus in CSF in the majority of the cases may suggest an alternative mechanism of COVID-19-provoked neurological complications.
Certain reports proposed that virus-provoked inflammation and immune response may have potential roles in neurologic manifestations in COVID-19 patients. SARS-CoV-2 has been revealed to trigger a "cytokine storm," which refers to an overproduction of pro-inflammatory cytokines. The extent of inflammation is directly associated with the severity of the infection. COVID-19-provoked activation of immune cells can consequently endorse several signal transductions, which further enhance cytokine production. COVID-19 patients with neurological complications exhibited a high extent of inflammation apparent from an elevated level of inflammatory markers and the presence of neuroinflammation in MRI scans. Thus, inflammation may have a potential role in neurologic manifestations in COVID-19 patients. However, more studies are required for a complete understanding of the exact pathological mechanism of the SARS-CoV-2 virus in developing neurologic manifestations. So far, no specific treatment is available to treat COVID-19-provoked neurologic manifestations; however, the proposed causative factors are generally targeted in the therapeutic management along with the drugs used for COVID-19 treatment.

The neurological complications in COVID-19 patients are not only restricted to acute effects but can also impart a sustained impact on the nervous system. Despite neurologic manifestation is directly associated with the disease severity and presence of comorbidities, it can also appear to the patients earlier to COVID-19 pneumonic/respiratory symptoms. Thus, special attention must be given to the neurologic patients as well as the COVID-19 patients without neurologic symptoms. Also, COVID-19 patients may be offered prophylactic therapy to protect them from or to delay neurologic manifestations. In conclusion, COVID19-manifested neurological complications are a serious issue, which requires substantial attention until a specific treatment is available.

Acknowledgements CSIR, New Delhi, India, is acknowledged for awarding a research project (02(0275)/16/EMR-II dated 06.12.2016) to SD. DBT, New Delhi, India, is sincerely acknowledged for Ramalingaswami Fellowship to RK. The authors sincerely acknowledge Jadavpur University, Kolkata, India, and CSIR-IICT, Hyderabad, India.

Author Contribution SD and RK contributed to the conceptualization and formatting of the article. SD, JV, RSK, NP, RK, and PHR are responsible for writing, original draft preparation, and finalization of the manuscript. SD, RK, and PHR are responsible for the funding acquisition.

Funding The research presented in this article was supported by the CSIR and DBT, India, and National Institutes of Health (NIH) grants USA, AG042178, AG047812, NS105473, AG060767, AG069333, AG066347, and R41 AG060836.

Data availability Not applicable. 


\section{Declarations}

Ethics Approval The presented research is in compliance with ethical standards.

Consent to Participate Not applicable.

Consent to Publish All authors agreed to publish the contents.

Conflict of Interest The authors declare no competing interests.

\section{References}

1. Abate G, Memo M, Uberti D (2020) Impact of COVID-19 on Alzheimer's disease risk: viewpoint for research action. Healthcare 8:286. https://doi.org/10.3390/healthcare8030286

2. Abdelhady M, Elsotouhy A, Vattoth S (2020) Acute flaccid myelitis in COVID-19. BJR/case reports 6(3):20200098. https://doi. org/10.1259/bjrcr.20200098

3. Achar A, Ghosh C (2020) COVID-19-associated neurological disorders: the potential route of CNS invasion and blood-brain barrier relevance. Cells 9(11):2360

4. Achbani A, Sine H, Naciri A, Baba MA, Kharbach A, Bouchriti Y, Nejmeddine M (2020) Can the 2019 novel coronavirus cause Parkinson's disease? Mov Disord 35(7):1102-1103. https://doi. org/10.1002/mds.28118

5. Agyeman AA, Chin KL, Landersdorfer CB, Liew D, OforiAsenso R (2020) Smell and taste dysfunction in patients with COVID-19: a systematic review and meta-analysis. Mayo Clin Proc 95(8):1621-1631. https://doi.org/10.1016/j.mayocp.2020. 05.030

6. Ahmad I, Rathore FA (2020) Neurological manifestations and complications of COVID-19: a literature review. Journal of Clinical Neuroscience: Official Journal of the Neurosurgical Society of Australasia 77:8-12. https://doi.org/10.1016/j.jocn.2020.05. 017

7. Al Mazrouei SS, Saeed GA, Al Helali AA, Ahmed M (2020) COVID-19-associated encephalopathy: neurological manifestation of COVID-19. Radiology Case Reports 15(9):1646-1649. https://doi.org/10.1016/j.radcr.2020.07.009

8. Alberti P, Beretta S, Piatti M, Karantzoulis A, Piatti ML, Santoro P, Viganò M, Giovannelli G, Pirro F, Montisano DA, Appollonio I, Ferrarese C (2020) Guillain-Barré syndrome related to COVID-19 infection. Neurology - Neuroimmunology Neuroinflammation 7(4):e741. https://doi.org/10.1212/nxi.0000000000 000741

9. AlKetbi R, AlNuaimi D, AlMulla M, AlTalai N, Samir M, Kumar N, AlBastaki U (2020) Acute myelitis as a neurological complication of Covid-19: a case report and MRI findings. Radiology Case Reports 15(9):1591-1595. https://doi.org/10.1016/j.radcr. 2020.06.001

10. Al-Lami RA, Urban RJ, Volpi E, Algburi AMA, Baillargeon J (2020) Sex hormones and novel corona virus infectious disease (COVID-19). Mayo Clin Proc 95(8):1710-1714. https://doi. org/10.1016/j.mayocp.2020.05.013

11. Altable M, De la Serna JM (2020) Cerebrovascular disease in COVID-19: is there a higher risk of stroke? Brain, Behavior, \& Immunity - Health 6:100092. https://doi.org/10.1016/j.bbih. 2020.100092

12. Altin F, Cingi C, Uzun T, Bal C (2020) Olfactory and gustatory abnormalities in COVID-19 cases. Eur Arch
Otorhinolaryngol 277(10):2775-2781. https://doi.org/10.1007/ s00405-020-06155-9

13. Antonini A, Leta V, Teo J, Chaudhuri KR (2020) Outcome of Parkinson's disease patients affected by COVID-19. Mov Disord 35(6):905-908. https://doi.org/10.1002/mds.28104

14. Araya-Quintanilla F, Valdés-Orrego I, Gutiérrez-Espinoza H (2021) Relation between COVID-19 and Guillain-Barre syndrome in adults. Systematic review. Neurologia (Barcelona, Spain) 36(2):183-184. https://doi.org/10.1016/j.nrl.2020.10. 002

15. Artusi C, Romagnolo A, Imbalzano G, Marchet A, Zibetti M, Rizzone M, Lopiano L (2020) COVID-19 in Parkinson's disease: report on prevalence and outcome. Parkinsonism Relat Disord 80:7-9. https://doi.org/10.1016/j.parkreldis.2020.09.008

16. Baker D, Amor S, Kang AS, Schmierer K, Giovannoni G (2020) The underpinning biology relating to multiple sclerosis disease modifying treatments during the COVID-19 pandemic. Multiple Sclerosis and Related Disorders 43:102174. https://doi.org/10. 1016/j.msard.2020.102174

17. Beghi E, Feigin V, Caso V, Santalucia P, Logroscino G (2020) COVID-19 infection and neurological complications: present findings and future predictions. Neuroepidemiology 54(5):364 369. https://doi.org/10.1159/000508991

18. Beltrán-Corbellini Á, Chico-García JL, Martínez-Poles J, Rodríguez-Jorge F, Natera-Villalba E, Gómez-Corral J, GómezLópez A, Monreal E, Parra-Díaz P, Cortés-Cuevas JL, Galán JC, Fragola-Arnau C, Porta-Etessam J, Masjuan J, Alonso-Cánovas A (2020) Acute-onset smell and taste disorders in the context of COVID-19: a pilot multicentre polymerase chain reaction based case-control study. Eur J Neurol 27(9):1738-1741. https://doi. org/10.1111/ene.14273

19. Bhavsar SM, Agarwal S, Lewis R, Ganta A, Roshchina YS, Clouser KN, Baer AZ, Gliksman F, Piwoz JA (2021) COVID19 infection associated with encephalitis in an adolescent. Neurol Clin Prac 11(2):e189-e192. https://doi.org/10.1212/cpj.00000 00000000911

20. Bost P, Giladi A, Liu Y, Bendjelal Y, Xu G, David E, BlecherGonen R, Cohen M, Medaglia C, Li H, Deczkowska A, Zhang S, Schwikowski B, Zhang Z, Amit I (2020) Host-viral infection maps reveal signatures of severe COVID-19 patients. Cell 181(7):1475-1488.e1412. https://doi.org/10.1016/J.CELL.2020. 05.006

21. Brundin P, Nath A, Beckham JD (2020) Is COVID-19 a perfect storm for Parkinson's disease? Trends Neurosci 43(12):931-933. https://doi.org/10.1016/j.tins.2020.10.009

22. Bsteh G, Bitschnau C, Hegen H, Auer M, Di Pauli F, Rommer P, Deisenhammer F, Berger T (2020) Multiple sclerosis and COVID-19: how many are at risk? Eur J Neurol. https://doi.org/ 10.1111/ene. 14555

23. Bueso T, Elmassry M, El Nawaa SEN, Ball S, Solis X, Test V (2020) COVID-19 infection complicated by Guillain-Barré syndrome: a case report. Chest 158(4):A522-A523. https://doi. org/10.1016/j.chest.2020.08.496

24. Cabezudo-García P, Ciano-Petersen NL, Mena-Vázquez N, PonsPons G, Castro-Sánchez MV, Serrano-Castro PJ (2020) Incidence and case fatality rate of COVID-19 in patients with active epilepsy. Neurology 95(10):e1417-e1425. https://doi.org/10.1212/ wnl.0000000000010033

25. Camelo-Filho AE, Silva AMS, Estephan EP, Zambon AA, Mendonça RH, Souza PVS, Pinto W, Oliveira ASB, Dangoni-Filho I, Pouza AFP, Valerio BCO, Zanoteli E (2020) Myasthenia gravis and COVID-19: clinical characteristics and outcomes. Front Neurol 11:1053. https://doi.org/10.3389/fneur.2020.01053

26. Canevelli M, Valletta M, Toccaceli Blasi M, Remoli G, Sarti G, Nuti F, Sciancalepore F, Ruberti E, Cesari M, Bruno G (2020) 
Facing dementia during the COVID-19 outbreak. J Am Geriatr Soc 68(8):1673-1676. https://doi.org/10.1111/jgs.16644

27. Cao X (2020) COVID-19: immunopathology and its implications for therapy. Nat Rev Immunol 20(5):269-270. https://doi.org/10. 1038/s41577-020-0308-3

28. Cao Y, Liu X, Xiong L, Cai K (2020) Imaging and clinical features of patients with 2019 novel coronavirus SARS-CoV-2: a systematic review and meta-analysis. J Med Virol 92(9):14491459. https://doi.org/10.1002/jmv.25822

29. Carrillo-Larco RM, Altez-Fernandez C, Ravaglia S, Vizcarra JA (2020) COVID-19 and Guillain-Barre syndrome: a systematic review of case reports. Wellcome Open Research 5:107. https:// doi.org/10.12688/wellcomeopenres.15987.2

30. Chakraborty U, Chandra A, Ray AK, Biswas P (2020) COVID19-associated acute transverse myelitis: a rare entity. BMJ Case Reports 13(8):238668. https://doi.org/10.1136/bcr-2020-238668

31. Chaudhry F, Bulka H, Rathnam AS, Said OM, Lin J, Lorigan H, Bernitsas E, Rube J, Korzeniewski SJ, Memon AB, Levy PD, Schultz L, Javed A, Lisak R, Cerghet M (2020) COVID-19 in multiple sclerosis patients and risk factors for severe infection. J Neurol Sci 418:117147. https://doi.org/10.1016/j.jns.2020.117147

32. Chaudhry ZL, Klenja D, Janjua N, Cami-Kobeci G, Ahmed BY (2020) COVID-19 and Parkinson's disease: shared inflammatory pathways under oxidative stress. Brain Sciences 10(11):807. https://doi.org/10.3390/brainsci10110807

33. Chen T, Wu D, Chen H, Yan W, Yang D, Chen G, Ma K, Xu D, Yu H, Wang H, Wang T, Guo W, Chen J, Ding C, Zhang X, Huang J, Han M, Li S, Luo X, Zhao J, Ning Q (2020) Clinical characteristics of 113 deceased patients with coronavirus disease 2019: retrospective study. BMJ (Clinical Research ed) 368:m1091. https://doi.org/10.1136/bmj.m1091

34. Chen TH (2020) Neurological involvement associated with COVID-19 infection in children. J Neurol Sci 418:117096. https://doi.org/10.1016/j.jns.2020.117096

35. Cilia R, Bonvegna S, Straccia G, Andreasi NG, Elia AE, Romito LM, Devigili G, Cereda E, Eleopra R (2020) Effects of COVID19 on Parkinson's disease clinical features: a community-based case-control study. Movement Disorders: Official Journal of the Movement Disorder Society 35(8):1287-1292. https://doi.org/ 10.1002/mds. 28170

36. Ciotti JR, Valtcheva MV, Cross AH (2020) Effects of MS diseasemodifying therapies on responses to vaccinations: a review. Mult Scler Relat Disord 45:102439. https://doi.org/10.1016/j.msard. 2020.102439

37. Conti P, Younes A (2020) Coronavirus COV-19/SARS-CoV-2 affects women less than men: clinical response to viral infection. J Biol Regul Homeost Agents 34(2):339-343. https://doi.org/10. 23812/Editorial-Conti-3

38. Crescenzo F, Marastoni D, Bovo C, Calabrese M (2020) Frequency and severity of COVID-19 in multiple sclerosis: a short single-site report from northern Italy. Mult Scler Relat Disord 44:102372. https://doi.org/10.1016/j.msard.2020.102372

39. Cure E, Cumhur Cure M (2020) Can dapagliflozin have a protective effect against COVID-19 infection? A hypothesis Diabetes \& Metabolic Syndrome 14(4):405-406. https://doi.org/10.1016/j. dsx.2020.04.024

40. Dalla Costa G, Leocani L, Montalban X, Guerrero AI, Sørensen PS, Magyari M, Dobson RJB, Cummins N, Narayan VA, Hotopf M, Comi G (2020) Real-time assessment of COVID19 prevalence among multiple sclerosis patients: a multicenter European study. Neurological Sciences: Official Journal of the Italian Neurological Society and of the Italian Society of Clinical Neurophysiology 41(7):1647-1650. https://doi.org/10.1007/ s10072-020-04519-x

41. Delamarre L, Gollion C, Grouteau G, Rousset D, Jimena G, Roustan J, Gaussiat F, Aldigé E, Gaffard C, Duplantier J, Martin
C, Fourcade O, Bost C, Fortenfant F, Delobel P, Martin-Blondel G, Pariente J, Bonneville F, Geeraerts T (2020) COVID-19-associated acute necrotising encephalopathy successfully treated with steroids and polyvalent immunoglobulin with unusual IgG targeting the cerebral fibre network. J Neurol Neurosurg Psychiatry 91(9): 1004-1006. https://doi.org/10.1136/jnnp-2020-323678

42. Delly F, Syed MJ, Lisak RP, Zutshi D (2020) Myasthenic crisis in COVID-19. J Neurol Sci 414:116888. https://doi.org/10.1016/j. jns.2020.116888

43. Derollez C, Alberto T, Leroi I, Mackowiak MA, Chen Y (2020) Facial nerve palsy: an atypical clinical manifestation of COVID19 infection in a family cluster. Eur J Neurol 27(12):2670-2672. https://doi.org/10.1111/ene.14493

44. Devlin JW, O'Neal HR Jr, Thomas C, Barnes Daly MA, Stollings JL, Janz DR, Ely EW, Lin JC (2020) Strategies to Optimize ICU Liberation (A to F) Bundle performance in critically ill adults with coronavirus disease 2019. Critical Care Explorations 2(6):e0139. https://doi.org/10.1097/cce.0000000000000139

45. Dinkin M, Gao V, Kahan J, Bobker S, Simonetto M, Wechsler P, Harpe J, Greer C, Mints G, Salama G, Tsiouris AJ, Leifer D (2020) COVID-19 presenting with ophthalmoparesis from cranial nerve palsy. Neurology 95(5):221-223. https://doi.org/10. 1212/wnl.0000000000009700

46. Dubé M, Le Coupanec A, Wong AHM, Rini JM, Desforges M, Talbot PJ (2018) Axonal transport enables neuron-to-neuron propagation of human coronavirus OC43. J Virol 92(17):e0040418. https://doi.org/10.1128/jvi.00404-18

47. Ellul MA, Benjamin L, Singh B, Lant S, Michael BD, Easton A, Kneen R, Defres S, Sejvar J, Solomon T (2020) Neurological associations of COVID-19. The Lancet Neurology 19(9):767783. https://doi.org/10.1016/s1474-4422(20)30221-0

48. Evangelou N, Garjani A, dasNair R, Hunter R, Tuite-Dalton KA, Craig EM, Rodgers WJ, Coles A, Dobson R, Duddy M, Ford DV, Hughes S, Pearson O, Middleton LA, Rog D, Tallantyre EC, Friede T, Middleton RM, Nicholas R, (2020) Self-diagnosed COVID-19 in people with multiple sclerosis: a community-based cohort of the UK MS Register. J Neurol Neurosurg Psychiatry 92(1):107-109. https://doi.org/10.1136/jnnp-2020-324449

49. Fan H, Tang X, Song Y, Liu P, Chen Y (2020) Influence of COVID-19 on cerebrovascular disease and its possible mechanism. Neuropsychiatr Dis Treat 16:1359-1367. https://doi.org/ 10.2147/ndt.s251173

50. Fasano A, Cereda E, Barichella M, Cassani E, Ferri V, Zecchinelli AL, Pezzoli G (2020) COVID-19 in Parkinson's disease patients living in Lombardy, Italy. Movement Disorders: Official Journal of the Movement Disorder Society 35(7):1089-1093. https://doi.org/10.1002/mds.28176

51. Ferini-Strambi L, Salsone M (2021) COVID-19 and neurological disorders: are neurodegenerative or neuroimmunological diseases more vulnerable? J Neurol 268(2):409-419. https://doi.org/10. 1007/s00415-020-10070-8

52. Ferraro S, Tuccori M, Convertino I, Valdiserra G, Cappello E, Maggi F, Blandizzi C, Focosi D (2020) Olfactory and gustatory impairments in COVID-19 patients: role in early diagnosis and interferences by concomitant drugs. Br J Clin Pharmacol. https:// doi.org/10.1111/bcp. 14634

53. Fifi JT, Mocco J (2020) COVID-19 related stroke in young individuals. The Lancet Neurology 19(9):713-715. https://doi. org/10.1016/s1474-4422(20)30272-6

54. Fonseca E, Quintana M, Lallana S, Luis Restrepo J, Abraira L, Santamarina E, Seijo-Raposo I, Toledo M (2020) Epilepsy in time of COVID-19: a survey-based study. Acta Neurol Scand 142(6):545-554. https://doi.org/10.1111/ane.13335

55. Fotuhi M, Mian A, Meysami S, Raji CA (2020) Neurobiology of COVID-19. Journal of Alzheimer's Disease: JAD 76(1):319. https://doi.org/10.3233/jad-200581 
56. Fraser JF, Arthur AS, Chen M, Levitt M, Mocco J, Albuquerque FC, Ansari SA, Dabus G, Jayaraman MV, Mack WJ, Milburn J, Mokin M, Narayanan S, Puri AS, Siddiqui AH, Tsai JP, Klucznik RP (2020) Society of NeuroInterventional Surgery recommendations for the care of emergent neurointerventional patients in the setting of COVID-19. Journal of Neurointerventional Surgery 12(6):539-541. https://doi.org/10.1136/neuri ntsurg-2020-016098

57. Fulzele S, Sahay B, Yusufu I, Lee TJ, Sharma A, Kolhe R, Isales CM (2020) COVID-19 virulence in aged patients might be impacted by the host cellular microRNAs abundance/profile. Aging Dis 11(3):509-522. https://doi.org/10.14336/ad.2020.0428

58. Gane SB, Kelly C, Hopkins C (2020) Isolated sudden onset anosmia in COVID-19 infection. A novel syndrome? Rhinology 58(3):299-301. https://doi.org/10.4193/Rhin20.114

59. Garg RK (2020) Spectrum of neurological manifestations in Covid-19: a review. Neurol India 68(3):560-572. https://doi. org/10.4103/0028-3886.289000

60. Garg RK, Paliwal VK, Gupta A (2021) Encephalopathy in patients with COVID-19: a review. J Med Virol 93(1):206-222. https://doi.org/10.1002/jmv.26207

61. Giacomelli A, Pezzati L, Conti F, Bernacchia D, Siano M, Oreni L, Rusconi S, Gervasoni C, Ridolfo AL, Rizzardini G, Antinori S, Galli M (2020) Self-reported olfactory and taste disorders in patients with severe acute respiratory coronavirus 2 infection: a cross-sectional study. Clinical Infectious Diseases: an Official Publication of the Infectious Diseases Society of America 71(15):889-890. https://doi.org/10.1093/cid/ciaa330

62. Guan W-j, Ni Z-y, Hu Y, Liang W-h, Ou C-q, He J-x, Liu L, Shan H, Lei C-1, Hui DSC, Du B, Li L-j, Zeng G, Yuen K-Y, Chen R-c, Tang C-1, Wang T, Chen P-y, Xiang J, Li S-y, Wang J-1, Liang Z-j, Peng Y-x, Wei L, Liu Y, Hu Y-h, Peng P, Wang J-m, Liu J-y, Chen Z, Li G, Zheng Z-j, Qiu S-q, Luo J, Ye C-j, Zhu S-y, Zhong $\mathrm{N}-\mathrm{s}$ (2020) Clinical characteristics of coronavirus disease 2019 in China. N Engl J Med 382(18):1708-1720. https://doi.org/10. 1056/NEJMoa2002032

63. Güler MA, Keskin F, Tan H (2020) Acute myelitis secondary to COVID-19 in an adolescent: causality or coincidence ? New Trends in Medicine Sciences 2(1):132-136

64. Haider A, Siddiqa A, Ali N, Dhallu M (2020) COVID-19 and the brain: acute encephalitis as a clinical manifestation. Cureus 12(10):e10784. https://doi.org/10.7759/cureus.10784

65. Helms J, Kremer S, Merdji H, Schenck M, Severac F, ClereJehl R, Studer A, Radosavljevic M, Kummerlen C, Monnier A, Boulay C, Fafi-Kremer S, Castelain V, Ohana M, Anheim M, Schneider F, Meziani F (2020) Delirium and encephalopathy in severe COVID-19: a cohort analysis of ICU patients. Critical Care (London, England) 24(1):491. https://doi.org/10.1186/ s13054-020-03200-1

66. Herman C, Mayer K, Sarwal A (2020) Scoping review of prevalence of neurologic comorbidities in patients hospitalized for COVID-19. Neurology 95(2):77-84. https://doi.org/10.1212/wnl. 0000000000009673

67. Hoang P, Hurtubise B, Muppidi S (2020) Clinical reasoning: therapeutic considerations in myasthenic crisis due to COVID-19 infection. Neurology 95(18):840-843. https://doi.org/10.1212/ wnl.0000000000010651

68. Hoffmann M, Kleine-Weber H, Schroeder S, Krüger N, Herrler T, Erichsen S, Schiergens TS, Herrler G, Wu NH, Nitsche A, Müller MA, Drosten C, Pöhlmann S (2020) SARS-CoV-2 cell entry depends on ACE2 and TMPRSS2 and is blocked by a clinically proven protease inhibitor. Cell 181(2):271-280.e278. https://doi. org/10.1016/j.cell.2020.02.052

69. Iadecola C, Anrather J, Kamel H (2020) Effects of COVID-19 on the nervous system. Cell 183(1):16-27.e11. https://doi.org/10. 1016/j.cell.2020.08.028
70. Inal J (2020) Biological factors linking ApoE $\varepsilon 4$ variant and severe COVID-19. Curr Atheroscler Rep 22(11):70. https://doi. org/10.1007/s11883-020-00896-y

71. Isaia G, Marinello R, Tibaldi V, Tamone C, Bo M (2020) Atypical presentation of Covid-19 in an older adult with severe Alzheimer disease. The American Journal of Geriatric Psychiatry: Official Journal of the American Association for Geriatric Psychiatry 28(7):790-791. https://doi.org/10.1016/j.jagp.2020.04. 018

72. Jacob S, Muppidi S, Guidon A, Guptill J, Hehir M, Howard JF Jr, Illa I, Mantegazza R, Murai H, Utsugisawa K, Vissing J, Wiendl H, Nowak RJ (2020) Guidance for the management of myasthenia gravis (MG) and Lambert-Eaton myasthenic syndrome (LEMS) during the COVID-19 pandemic. J Neurol Sci 412:116803. https://doi.org/10.1016/j.jns.2020.116803

73. Jin JM, Bai P, He W, Wu F, Liu XF, Han DM, Liu S, Yang JK (2020) Gender differences in patients with COVID-19: focus on severity and mortality. Front Public Health 8:152. https://doi.org/ 10.3389/fpubh.2020.00152

74. Kai H, Kai M (2020) Interactions of coronaviruses with ACE2, angiotensin II, and RAS inhibitors-lessons from available evidence and insights into COVID-19. Hypertension Research: Official Journal of the Japanese Society of Hypertension 43(7):648654. https://doi.org/10.1038/s41440-020-0455-8

75. Kalra RS, Chaudhary A, Yoon AR, Bhargava P, Omar A, Garg S, Yun CO, Kaul SC, Wadhwa R (2018) CARF enrichment promotes epithelial-mesenchymal transition via $\mathrm{Wnt} / \beta$-catenin signaling: its clinical relevance and potential as a therapeutic target. Oncogenesis 7(5):39. https://doi.org/10.1038/s41389-018-0048-4

76. Kalra RS, Kandimalla R (2021) Engaging the spikes: heparan sulfate facilitates SARS-CoV-2 spike protein binding to ACE2 and potentiates viral infection. Signal Transduct Target Ther 6(1):39. https://doi.org/10.1038/s41392-021-00470-1

77. Kalra RS, Kumar V, Dhanjal JK, Garg S, Li X, Kaul SC, Sundar D, Wadhwa R (2021) COVID19-inhibitory activity of withanolides involves targeting of the host cell surface receptor ACE2: insights from computational and biochemical assays. J Biomol Struc Dyn 2(1):14. https://doi.org/10.1080/07391102.2021.1902858

78. Kalra RS, Tomar D, Meena AS, Kandimalla R (2020) SARSCoV-2, ACE2, and hydroxychloroquine: cardiovascular complications, therapeutics, and clinical readouts in the current settings. Pathogens 9(7):546. https://doi.org/10.3390/pathogens9070546

79. Kaur H, Mason JA, Bajracharya M, McGee J, Gunderson MD, Hart BL, Dehority W, Link N, Moore B, Phillips JP, Rogers D (2020) Transverse myelitis in a child with COVID-19. Pediatr Neurol 112:5-6. https://doi.org/10.1016/j.pediatrneurol.2020.07. 017

80. Kehoe PG, Wong S, Al Mulhim N, Palmer LE, Miners JS (2016) Angiotensin-converting enzyme 2 is reduced in Alzheimer's disease in association with increasing amyloid- $\beta$ and tau pathology. Alzheimer's Research \& Therapy 8(1):50. https://doi.org/ 10.1186/s13195-016-0217-7

81. Kihira S, Delman BN, Belani P, Stein L, Aggarwal A, Rigney B, Schefflein J, Doshi AH, Pawha PS (2020) Imaging features of acute encephalopathy in patients with COVID-19: a case series. AJNR Am J Neuroradiol 41(10):1804-1808. https://doi.org/10. 3174/ajnr.A6715

82. Kim Y, Walser SA, Asghar SJ, Jain R, Mainali G, Kumar A (2021) A comprehensive review of neurologic manifestations of COVID-19 and management of pre-existing neurologic disorders in children. J Child Neurol 36(4):324-330. https://doi.org/10. 1177/0883073820968995

83. Kinikar A, Kulkarni R, Rajput U, Karyakarte R (2020) Acute encephalopathy in a child with coronavirus disease- 2019 infection. Pediatr Infect Dis 2:62-63. https://doi.org/10.5005/jp-journ als-10081-1244 
84. Kloc M, Ghobrial RM (2020) The multiple sclerosis (MS) drugs as a potential treatment of ARDS in COVID-19 patients. Mult Scler Relat Disord 45:102437. https://doi.org/10.1016/j.msard. 2020.102437

85. Klok FA, Kruip M, van der Meer NJM, Arbous MS, Gommers D, Kant KM, Kaptein FHJ, van Paassen J, Stals MAM, Huisman MV, Endeman H (2020) Incidence of thrombotic complications in critically ill ICU patients with COVID-19. Thromb Res 191:145-147. https://doi.org/10.1016/j.thromres.2020.04.013

86. Konar A, Kalra RS, Chaudhary A, Nayak A, Guruprasad KP, Satyamoorthy K, Ishida Y, Terao K, Kaul SC, Wadhwa R (2020) Identification of caffeic acid phenethyl ester (CAPE) as a potent neurodifferentiating natural compound that improves cognitive and physiological functions in animal models of neurodegenerative diseases. Frontiers in Aging Neuroscience 12:561925. https://doi.org/10.3389/fnagi.2020.561925

87. Kucuk A, Cumhur Cure M, Cure E (2020) Can COVID-19 cause myalgia with a completely different mechanism? A hypothesis Clinical Rheumatology 39(7):2103-2104. https://doi.org/10. 1007/s10067-020-05178-1

88. Lee Y, Min P, Lee S, Kim SW (2020) Prevalence and duration of acute loss of smell or taste in COVID-19 patients. J Korean Med Sci 35(18):e174. https://doi.org/10.3346/jkms.2020.35.e174

89. Li HF, Hao HJ, Chen XJ (2020) Provisional case definitions for COVID-19-associated neurological disease. The Lancet Neurology 19(11):890-891. https://doi.org/10.1016/s1474-4422(20)30373-2

90. Li J, Gao J, Xu YP, Zhou TL, Jin YY, Lou JN (2007) Expression of severe acute respiratory syndrome coronavirus receptors, ACE2 and CD209L in different organ derived microvascular endothelial cells. Zhonghua Yi Xue Za Zhi 87(12):833-837

91. Li J, Long X, Huang H, Tang J, Zhu C, Hu S, Wu J, Li J, Lin Z, Xiong N (2020) Resilience of Alzheimer's disease to COVID-19. Journal of Alzheimer's Disease: JAD 77(1):67-73. https://doi. org/10.3233/jad-200649

92. Li J, Sun Y, Chen J (2019) Transcriptome sequencing in a 6-hydroxydopamine rat model of Parkinson's disease. Genes Genet Syst 94(2):61-69. https://doi.org/10.1266/ggs.18-00036

93. Li L, Gao R, Yu Y, Kaul Z, Wang J, Kalra RS, Zhang Z, Kaul SC, Wadhwa R (2018) Tumor suppressor activity of miR-451: identification of CARF as a new target. Sci Rep 8(1):375. https:// doi.org/10.1038/s41598-017-18559-5

94. Li Y, Li M, Wang M, Zhou Y, Chang J, Xian Y, Wang D, Mao L, Jin H, Hu B (2020) Acute cerebrovascular disease following COVID-19: a single center, retrospective, observational study. Stroke and Vascular Neurology 5(3):279-284. https://doi.org/ 10.1136/svn-2020-000431

95. Li Z, Liu T, Yang N, Han D, Mi X, Li Y, Liu K, Vuylsteke A, Xiang H, Guo X (2020) Neurological manifestations of patients with COVID-19: potential routes of SARS-CoV-2 neuroinvasion from the periphery to the brain. Frontiers of Medicine 14(5):533541. https://doi.org/10.1007/s11684-020-0786-5

96. Lima M, Siokas V, Aloizou AM, Liampas I, Mentis AA, Tsouris Z, Papadimitriou A, Mitsias PD, Tsatsakis A, Bogdanos DP, Baloyannis SJ, Dardiotis E (2020) Unraveling the possible routes of SARS-COV-2 invasion into the central nervous system. Curr Treat Options Neurol 22(11):37. https://doi.org/10.1007/ s11940-020-00647-z

97. Liotta EM, Batra A, Clark JR, Shlobin NA, Hoffman SC, Orban ZS, Koralnik IJ (2020) Frequent neurologic manifestations and encephalopathy-associated morbidity in Covid-19 patients. Annals of Clinical and Translational Neurology 7(11):22212230. https://doi.org/10.1002/acn3.51210

98. Lippi G, Wong J, Henry BM (2020) Myalgia may not be associated with severity of coronavirus disease 2019 (COVID-19). World J Emerg Med 11(3):193-194. https://doi.org/10.5847/ wjem.j.1920-8642.2020.03.013
99. Lodigiani C, Iapichino G, Carenzo L, Cecconi M, Ferrazzi P, Sebastian T, Kucher N, Studt JD, Sacco C, Bertuzzi A, Sandri MT, Barco S (2020) Venous and arterial thromboembolic complications in COVID-19 patients admitted to an academic hospital in Milan, Italy. Thromb Res 191:9-14. https://doi.org/ 10.1016/j.thromres.2020.04.024

100. Loonstra FC, Hoitsma E, van Kempen ZL, Killestein J, Mostert JP (2020) COVID-19 in multiple sclerosis: the Dutch experience. Multiple Sclerosis (Houndmills, Basingstoke, England) 26(10):1256-1260. https://doi.org/10.1177/1352458520942198

101. Lorenzo Villalba N, Maouche Y, Alonso Ortiz MB, Cordoba Sosa Z, Chahbazian JB, Syrovatkova A, Pertoldi P, Andres E, Zulfiqar AA (2020) Anosmia and dysgeusia in the absence of other respiratory diseases: should COVID-19 infection be considered? European Journal of Case Reports in Internal Medicine 7(4):001641. https://doi.org/10.12890/2020_001641

102. Louapre C, Collongues N, Stankoff B, Giannesini C, Papeix C, Bensa C, Deschamps R, Créange A, Wahab A, Pelletier J, Heinzlef O, Labauge P, Guilloton L, Ahle G, Goudot M, Bigaut K, Laplaud DA, Vukusic S, Lubetzki C, De Sèze J, Derouiche F, Tourbah A, Mathey G, Théaudin M, Sellal F, Dugay MH, Zéphir H, Vermersch P, Durand-Dubief F, Françoise R, Androdias-Condemine G, Pique J, Codjia P, Tilikete C, Marcaud V, Lebrun-Frenay C, Cohen M, Ungureanu A, Maillart E, Beigneux Y, Roux T, Corvol JC, Bordet A, Mathieu Y, Le Breton F, Boulos DD, Gout O, Guéguen A, Moulignier A, Boudot M, Chardain A, Coulette S, Manchon E, Ayache SS, Moreau T, Garcia PY, Kumaran D, Castelnovo G, Thouvenot E, Taithe F, Poupart J, Kwiatkowski A, Defer G, Derache N, Branger P, Biotti D, Ciron J, Clerc C, Vaillant M, Magy L, Montcuquet A, Kerschen P, Coustans M, Guennoc AM, Brochet B, Ouallet JC, Ruet A, Dulau C, Wiertlewski S, Berger E, Buch D, Bourre B, Pallix-Guiot M, Maurousset A, Audoin B, Rico A, Maarouf A, Edan G, Papassin J, Videt D (2020) Clinical characteristics and outcomes in patients with coronavirus disease 2019 and multiple sclerosis. JAMA Neurol 77(9):1079-1088. https://doi.org/10.1001/jaman eurol.2020.2581

103. Lovell N, Maddocks M, Etkind SN, Taylor K, Carey I, Vora V, Marsh L, Higginson IJ, Prentice W, Edmonds P, Sleeman KE (2020) Characteristics, symptom management, and outcomes of 101 patients with COVID-19 referred for hospital palliative care. J Pain Symptom Manage 60(1):e77-e81. https://doi.org/10. 1016/j.jpainsymman.2020.04.015

104. Lozada-Nur F, Chainani-Wu N, Fortuna G, Sroussi H (2020) Dysgeusia in COVID-19: possible mechanisms and implications. Oral Surg Oral Med Oral Pathol Oral Radiol 130(3):344-346. https://doi.org/10.1016/j.oooo.2020.06.016

105. Lucchese G, Flöel A (2020) SARS-CoV-2 and Guillain-Barré syndrome: molecular mimicry with human heat shock proteins as potential pathogenic mechanism. Cell Stress Chaperones 25(5):731-735. https://doi.org/10.1007/s12192-020-01145-6

106. Ma C, Wu X, Shen X, Yang Y, Chen Z, Sun X, Wang Z (2019) Sex differences in traumatic brain injury: a multi-dimensional exploration in genes, hormones, cells, individuals, and society. Chinese Neurosurgical Journal 5:24. https://doi.org/10.1186/ s41016-019-0173-8

107. Mallucci G, Zito A, Fabbro BD, Bergamaschi R (2020) Asymptomatic SARS-CoV-2 infection in two patients with multiple sclerosis treated with fingolimod. Mult Scler Relat Disord 45:102414. https://doi.org/10.1016/j.msard.2020.102414

108. Mansoor S, Kelly S, Murphy K, Waters A, Siddiqui NS (2020) COVID-19 pandemic and the risk of infection in multiple sclerosis patients on disease modifying therapies: "what the bleep do we know?" The Egyptian Journal of Neurology, Psychiatry and Neurosurgery 56(1):44. https://doi.org/10.1186/ s41983-020-00177-0 
109. Mao L, Jin H, Wang M, Hu Y, Chen S, He Q, Chang J, Hong C, Zhou Y, Wang D, Miao X, Li Y, Hu B (2020) Neurologic manifestations of hospitalized patients with coronavirus disease 2019 in Wuhan. China JAMA Neurology 77(6):683-690. https://doi. org/10.1001/jamaneurol.2020.1127

110. Maramattom BV, Bhattacharjee S (2020) Neurological complications with COVID-19: a contemporaneous review. Ann Indian Acad Neurol 23(4):468-476. https://doi.org/10.4103/aian.AIAN_ 596_20

111. McAbee GN, Brosgol Y, Pavlakis S, Agha R, Gaffoor M (2020) Encephalitis associated with COVID-19 infection in an 11-yearold child. Pediatr Neurol 109:94. https://doi.org/10.1016/j.pedia trneurol.2020.04.013

112. Meca-Lallana V, Aguirre C, Beatrizdel R, Cardeñoso L, Alarcon T, Vivancos J (2020) COVID-19 in 7 multiple sclerosis patients in treatment with ANTI-CD20 therapies. Mult Scler Relat Disord 44:102306. https://doi.org/10.1016/j.msard.2020.102306

113. Meegada S, Muppidi V, Wilkinson DC 3rd, Siddamreddy S, Katta SK (2020) Coronavirus disease 2019-induced rhabdomyolysis. Cureus 12(8):e10123. https://doi.org/10.7759/cureus. 10123

114. Meinhardt J, Radke J, Dittmayer C, Franz J, Thomas C, Mothes R, Laue M, Schneider J, Brünink S, Greuel S, Lehmann M, Hassan O, Aschman T, Schumann E, Chua RL, Conrad C, Eils R, Stenzel W, Windgassen M, Rößler L, Goebel HH, Gelderblom HR, Martin H, Nitsche A, Schulz-Schaeffer WJ, Hakroush S, Winkler MS, Tampe B, Scheibe F, Körtvélyessy P, Reinhold D, Siegmund B, Kühl AA, Elezkurtaj S, Horst D, Oesterhelweg L, Tsokos M, Ingold-Heppner B, Stadelmann C, Drosten C, Corman VM, Radbruch H, Heppner FL (2021) Olfactory transmucosal SARS-CoV-2 invasion as a port of central nervous system entry in individuals with COVID-19. Nat Neurosci 24(2):168-175. https://doi.org/10.1038/s41593-020-00758-5

115. Moein ST, Hashemian SM, Mansourafshar B, Khorram-Tousi A, Tabarsi P, Doty RL (2020) Smell dysfunction: a biomarker for COVID-19. International Forum of Allergy \& Rhinology 10(8):944-950. https://doi.org/10.1002/alr.22587

116. Montalvan V, Lee J, Bueso T, De Toledo J, Rivas K (2020) Neurological manifestations of COVID-19 and other coronavirus infections: a systematic review. Clin Neurol Neurosurg 194:105921. https://doi.org/10.1016/j.clineuro.2020.105921

117. Moriguchi T, Harii N, Goto J, Harada D, Sugawara H, Takamino J, Ueno M, Sakata H, Kondo K, Myose N, Nakao A, Takeda M, Haro H, Inoue O, Suzuki-Inoue K, Kubokawa K, Ogihara S, Sasaki T, Kinouchi H, Kojin H, Ito M, Onishi H, Shimizu T, Sasaki Y, Enomoto N, Ishihara H, Furuya S, Yamamoto T, Shimada $S$ (2020) A first case of meningitis/encephalitis associated with SARS-Coronavirus-2. International Journal of Infectious Diseases: IJID: Official Publication of the International Society for Infectious Diseases 94:55-58. https://doi.org/10.1016/j.ijid. 2020.03.062

118. Moschella P, Roth P (2020) Isolated COVID-19 infection precipitates myasthenia gravis crisis: a case report. Clinical Practice and Cases in Emergency Medicine 4(4):524-526. https:// doi.org/10.5811/cpcem.2020.9.49049

119. Muppidi S, Guptill JT, Jacob S, Li Y, Farrugia ME, Guidon AC, Tavee JO, Kaminski H, Howard JF Jr, Cutter G, Wiendl H, Maas MB, Illa I, Mantegazza R, Murai H, Utsugisawa K, Nowak RJ (2020) COVID-19-associated risks and effects in myasthenia gravis (CARE-MG). The Lancet Neurology 19(12):970-971. https://doi.org/10.1016/s1474-4422(20)30413-0

120. Najjar S, Najjar A, Chong DJ, Pramanik BK, Kirsch C, Kuzniecky RI, Pacia SV, Azhar S (2020) Central nervous system complications associated with SARS-CoV-2 infection: integrative concepts of pathophysiology and case reports. J Neuroinflammation 17(1):231. https://doi.org/10.1186/s12974-020-01896-0
121. Nanda S, Handa R, Prasad A, Anand R, Zutshi D, Dass SK, Bedi PK, Pahuja A, Shah PK, Sharma B (2021) Covid-19 associated Guillain-Barre syndrome: contrasting tale of four patients from a tertiary care centre in India. Am J Emerg Med 39:125-128. https://doi.org/10.1016/j.ajem.2020.09.029

122. Nannoni S, de Groot R, Bell S, Markus HS (2021) Stroke in COVID-19: A systematic review and meta-analysis. International Journal of Stroke: Official Journal of the International Stroke Society 16(2):137-149. https://doi.org/10.1177/1747493020972922

123. Naughton SX, Raval U, Pasinetti GM (2020) Potential novel role of COVID-19 in Alzheimer's disease and preventative mitigation strategies. Journal of Alzheimer's Disease: JAD 76(1):21-25. https://doi.org/10.3233/jad-200537

124. Niazkar HR, Zibaee B, Nasimi A, Bahri N (2020) The neurological manifestations of COVID-19: a review article. Neurological Sciences: Official Journal of the Italian Neurological Society and of the Italian Society of Clinical Neurophysiology 41(7):16671671. https://doi.org/10.1007/s10072-020-04486-3

125. Nouchi A, Chastang J, Miyara M, Lejeune J, Soares A, Ibanez G, Saadoun D, Morélot-Panzini C, Similowski T, Amoura Z, Boddaert J, Caumes E, Bleibtreu A, Lorenzo A, Tubach F, Pourcher V (2021) Prevalence of hyposmia and hypogeusia in 390 COVID-19 hospitalized patients and outpatients: a crosssectional study. European Journal of Clinical Microbiology \& Infectious Diseases: Official Publication of the European Society of Clinical Microbiology 40(4):691-697. https://doi.org/10.1007/ s10096-020-04056-7

126. Novi G, Mikulska M, Briano F, Toscanini F, Tazza F, Uccelli A, Inglese M (2020) COVID-19 in a MS patient treated with ocrelizumab: does immunosuppression have a protective role? Mult Scler Relat Disord 42:102120. https://doi.org/10.1016/j.msard. 2020.102120

127. Onder G, Rezza G, Brusaferro S (2020) Case-fatality rate and characteristics of patients dying in relation to COVID-19 in Italy. JAMA 323(18):1775-1776. https://doi.org/10.1001/jama.2020. 4683

128. Orrù G, Conversano C, Malloggi E, Francesconi F, Ciacchini R, Gemignani A (2020) Neurological complications of COVID-19 and possible neuroinvasion pathways: a systematic review. Int $\mathbf{J}$ Environ Res Public Health 17(18):6688. https://doi.org/10.3390/ ijerph17186688

129. Orsucci D, Ienco EC, Nocita G, Napolitano A, Vista M (2020) Neurological features of COVID-19 and their treatment: a review. Drugs in Context 9(5):1. https://doi.org/10.7573/dic.2020-5-1

130. P B (2020) Nearly one-third of Covid-19 patients in study had altered mental state. The New York Times. https://www.nytim es.com/2020/10/05/health/Covid-patients-mental-state.html. Accessed 31 Dec 2020

131. Palao M, Fernández-Díaz E, Gracia-Gil J, Romero-Sánchez CM, Díaz-Maroto I, Segura T (2020) Multiple sclerosis following SARS-CoV-2 infection. Mult Scler Relat Disord 45:102377. https://doi.org/10.1016/j.msard.2020.102377

132. Paniz-Mondolfi A, Bryce C, Grimes Z, Gordon RE, Reidy J, Lednicky J, Sordillo EM, Fowkes M (2020) Central nervous system involvement by severe acute respiratory syndrome coronavirus-2 (SARS-CoV-2). J Med Virol 92(7):699-702. https://doi.org/10. 1002/jmv.25915

133. Parihar J, Tripathi M, Dhamija RK (2020) Seizures and epilepsy in times of corona virus disease 2019 pandemic. Journal of Epilepsy Research 10(1):3-7. https://doi.org/10.14581/jer.20002

134. Park MD (2020) Macrophages: a Trojan horse in COVID19? Nat Rev Immunol 20(6):351. https://doi.org/10.1038/ s41577-020-0317-2

135. Parrotta E, Kister I, Charvet L, Sammarco C, Saha V, Charlson RE, Howard J, Gutman JM, Gottesman M, Abou-Fayssal N, Wolintz R, Keilson M, Fernandez-Carbonell C, Krupp LB, 
Zhovtis Ryerson L (2020) COVID-19 outcomes in MS: observational study of early experience from NYU Multiple Sclerosis Comprehensive Care Center. Neurol Neuroimmunol Neuroinflamm 7(5):e835

136. Pavel A, Murray DK, Stoessl AJ (2020) COVID-19 and selective vulnerability to Parkinson's disease. The Lancet Neurology 19(9):719. https://doi.org/10.1016/s1474-4422(20)30269-6

137. Pilotto A, Masciocchi S, Volonghi I, Crabbio M, Magni E, De Giuli V, Caprioli F, Rifino N, Sessa M, Gennuso M, Cotelli MS, Turla M, Balducci U, Mariotto S, Ferrari S, Ciccone A, Fiacco F, Imarisio A, Risi B, Benussi A, Premi E, Focà E, Caccuri F, Leonardi M, Gasparotti R, Castelli F, Zanusso G, Pezzini A, Padovani A (2021) Clinical presentation and outcomes of severe acute respiratory syndrome coronavirus 2-related encephalitis: the ENCOVID Multicenter Study. J Infect Dis 223(1):28-37. https://doi.org/10.1093/infdis/jiaa609

138. Pradhan A, Olsson PE (2020) Sex differences in severity and mortality from COVID-19: are males more vulnerable? Biol Sex Differ 11(1):53. https://doi.org/10.1186/s13293-020-00330-7

139. Prasad S, Holla VV, Neeraja K, Surisetti BK, Kamble N, Yadav R, Pal PK (2020) Parkinson's disease and COVID-19: perceptions and implications in patients and caregivers. Movement Disorders: Official Journal of the Movement Disorder Society 35(6):912-914. https://doi.org/10.1002/mds.28088

140. Qi X, Keith KA, Huang JH (2020) COVID-19 and stroke: a review. Brain Hemorrhages. https://doi.org/10.1016/j.hest.2020. 11.001

141. Rahimi K (2020) Guillain-Barre syndrome during COVID-19 pandemic: an overview of the reports. Neurological Sciences: Official Journal of the Italian Neurological Society and of the Italian Society of Clinical Neurophysiology 41(11):3149-3156. https://doi.org/10.1007/s10072-020-04693-y

142. Rahman MA, Islam K, Rahman S, Alamin M (2021) Neurobiochemical cross-talk between COVID-19 and Alzheimer's disease. Mol Neurobiol 58(3):1017-1023. https://doi.org/10.1007/ s12035-020-02177-w

143. Ramanathan K, Antognini D, Combes A, Paden M, Zakhary B, Ogino M, MacLaren G, Brodie D, Shekar K (2020) Planning and provision of ECMO services for severe ARDS during the COVID-19 pandemic and other outbreaks of emerging infectious diseases. Lancet Respir Med 8(5):518-526. https://doi.org/10. 1016/s2213-2600(20)30121-1

144. Ramaswamy SB, Govindarajan R (2020) COVID-19 in refractory myasthenia gravis- a case report of successful outcome. Journal of Neuromuscular Diseases 7(3):361-364. https://doi.org/10. 3233/jnd-200520

145. Reddy ST, Garg T, Shah C, Nascimento FA, Imran R, Kan P, Bowry R, Gonzales N, Barreto A, Kumar A, Volpi J, Misra V, Chiu D, Gadhia R, Savitz SI (2020) Cerebrovascular disease in patients with COVID-19: a review of the literature and case series. Case Reports in Neurology 12(2):199-209. https://doi. org/10.1159/000508958

146. Romero-Sánchez CM, Díaz-Maroto I, Fernández-Díaz E, Sánchez-Larsen Á, Layos-Romero A, García-García J, González E, Redondo-Peñas I, Perona-Moratalla AB, Del Valle-Pérez JA, Gracia-Gil J, Rojas-Bartolomé L, Feria-Vilar I, Monteagudo M, Palao M, Palazón-García E, Alcahut-Rodríguez C, SopelanaGaray D, Moreno Y, Ahmad J, Segura T (2020) Neurologic manifestations in hospitalized patients with COVID-19: the ALBACOVID registry. Neurology 95(8):e1060-e1070. https:// doi.org/10.1212/wnl.0000000000009937

147. Rostami Mansoor S, Ghasemi-Kasman M (2021) Impact of disease-modifying drugs on the severity of COVID-19 infection in multiple sclerosis patients. J Med Virol 93(3):1314-1319. https://doi.org/10.1002/jmv.26593
148. Roy ER, Wang B, Wan YW, Chiu G, Cole A, Yin Z, Propson NE, Xu Y, Jankowsky JL, Liu Z, Lee VM, Trojanowski JQ, Ginsberg SD, Butovsky O, Zheng H, Cao W (2020) Type I interferon response drives neuroinflammation and synapse loss in Alzheimer disease. J Clin Investig 130(4):1912-1930. https://doi.org/10.1172/jci133737

149. Sadeghmousavi S, Rezaei N (2020) COVID-19 and multiple sclerosis: predisposition and precautions in treatment. SN Compr Clin Med 3:1-6. https://doi.org/10.1007/ s42399-020-00504-9

150. Sainz-Amo R, Baena-Álvarez B, Pareés I, Sánchez-Díez G, Pérez-Torre P, López-Sendón JL, Fanjul-Arbos S, Monreal E, Corral-Corral I, García-Barragán N, Martínez-Castrillo JC, Fasano A, Alonso-Cánovas A (2020) COVID-19 in Parkinson's disease: what holds the key? Journal of Neurology:1-5. doi:https:// doi.org/10.1007/s00415-020-10272-0

151. Samaranayake LP, Fakhruddin KS, Panduwawala C (2020) Sudden onset, acute loss of taste and smell in coronavirus disease 2019 (COVID-19): a systematic review. Acta Odontol Scand 78(6):467-473. https://doi.org/10.1080/00016357.2020.1787505

152. Sanders BJ, Bakar M, Mehta S, Reid MC, Siegler EL, Abrams RC, Adelman RD, Lachs MS (2020) Hyperactive delirium requires more aggressive management in patients with COVID19: temporarily rethinking "low and slow." J Pain Symptom Manage 60(2):e31-e32. https://doi.org/10.1016/j.jpainsymman. 2020.05.013

153. Shahali H, Ghasemi A, Farahani RH, Nezami Asl A, Hazrati E (2021) Acute transverse myelitis after SARS-CoV-2 infection: a rare complicated case of rapid onset paraplegia. J Neurovirol 27(2):354-358. https://doi.org/10.1007/s13365-021-00957-1

154. Sharma K, Tengsupakul S, Sanchez O, Phaltas R, Maertens P (2019) Guillain-Barré syndrome with unilateral peripheral facial and bulbar palsy in a child: a case report. SAGE Open Med Case Rep 21(7):2050313x19838750. https://doi.org/10.1177/20503 $13 \times 19838750$

155. Shastri A, Wheat J, Agrawal S, Chaterjee N, Pradhan K, Goldfinger M, Kornblum N, Steidl U, Verma A, Shastri J (2020) Delayed clearance of SARS-CoV2 in male compared to female patients: high ACE2 expression in testes suggests possible existence of gender-specific viral reservoirs. medR xiv:2020.2004.2016.20060566. doi:https://doi.org/10.1101/2020. 04.16 .20060566

156. Speth MM, Singer-Cornelius T, Oberle M, Gengler I, Brockmeier SJ, Sedaghat AR (2020) Olfactory dysfunction and sinonasal symptomatology in COVID-19: prevalence, severity, timing, and associated characteristics. Otolaryngology-Head and Neck Surgery: Official Journal of American Academy of OtolaryngologyHead and Neck Surgery 163(1):114-120. https://doi.org/10.1177/ 0194599820929185

157. Srijon SS, Khanam R, Mimi AF (2020) Patient with COVID - 19 infection presenting with acute 6th cranial nerve palsy: a case report. Bangladesh Critical Care Journal 8(2):129-130

158. Su S, Cui H, Wang T, Shen X, Ma C (2020) Pain: a potential new label of COVID-19. Brain Behav Immun 87:159-160. https://doi.org/10.1016/j.bbi.2020.05.025

159. Sun M, Ruan X, Li Y, Wang P, Zheng S, Shui G, Li L, Huang Y, Zhang H (2021) Clinical characteristics of 30 COVID-19 patients with epilepsy: a retrospective study in Wuhan. International Journal of Infectious Diseases: IJID: Official Publication of the International Society for Infectious Diseases 103:647653. https://doi.org/10.1016/j.ijid.2020.09.1475

160. Sweid A, Hammoud B, Weinberg JH, Oneissi M, Raz E, Shapiro M, DePrince M, Tjoumakaris S, Gooch MR, Herial NA, Zarzour H, Romo V, Rosenwasser RH, Jabbour P (2020) Letter: Thrombotic neurovascular disease in COVID-19 patients. 
Neurosurgery 87(3):E400-e406. https://doi.org/10.1093/neuros/nyaa254

161. Tang X, Luo Y, Song Y, Fan H, Dong S, Liu P, Chen Y (2020) Neurological manifestations in COVID-19 and its possible mechanism. Aging 12(18):18754-18764. https://doi.org/10.18632/ aging. 103732

162. Taxbro K, Kahlow H, Wulcan H, Fornarve A (2020) Rhabdomyolysis and acute kidney injury in severe COVID-19 infection. BMJ Case Rep 13(9):e237616. https://doi.org/10.1136/ bcr-2020-237616

163. Umapathi T, Quek WMJ, Yen JM, Khin HSW, Mah YY, Chan CYJ, Ling LM, Yu WY (2020) Encephalopathy in COVID19 patients; viral, parainfectious, or both? eNeurologicalSci 21:100275. doi:https://doi.org/10.1016/j.ensci.2020.100275

164. Valiuddin H, Skwirsk B, Paz-Arabo P (2020) Acute transverse myelitis associated with SARS-CoV-2: a case-report. Brain Behav Immun Health 5:100091. https://doi.org/10.1016/j.bbih. 2020.100091

165. Varatharaj A, Thomas N, Ellul MA, Davies NWS, Pollak TA, Tenorio EL, Sultan M, Easton A, Breen G, Zandi M, Coles JP, Manji H, Al-Shahi Salman R, Menon DK, Nicholson TR, Benjamin LA, Carson A, Smith C, Turner MR, Solomon T, Kneen R, Pett SL, Galea I, Thomas RH, Michael BD (2020) Neurological and neuropsychiatric complications of COVID-19 in 153 patients: a UK-wide surveillance study. The Lancet Psychiatry 7(10):875-882. https://doi.org/10.1016/s2215-0366(20)30287-x

166. Vohora D, Jain S, Tripathi M, Potschka H (2020) COVID-19 and seizures: is there a link? Epilepsia 61(9):1840-1853. https://doi. org/10.1111/epi.16656

167. Wang B, Li R, Lu Z, Huang Y (2020) Does comorbidity increase the risk of patients with COVID-19: evidence from meta-analysis. Aging 12(7):6049-6057. https://doi.org/10.18632/aging. 103000

168. Wei H, Yin H, Huang M, Guo Z (2020) The 2019 novel cornoavirus pneumonia with onset of oculomotor nerve palsy: a case study. J Neurol 267(5):1550-1553. https://doi.org/10.1007/ s00415-020-09773-9

169. Wojkowska DW, Szpakowski P, Glabinski A (2017) Interleukin 17A promotes lymphocytes adhesion and induces CCL2 and CXCL1 release from brain endothelial cells. Int J Mol Sci 18(5):1000. https://doi.org/10.3390/ijms 18051000

170. Wu D, Yang XO (2020) TH17 responses in cytokine storm of COVID-19: an emerging target of JAK2 inhibitor Fedratinib. J Microbiol Immunol Infect 53(3):368-370. https://doi.org/10. 1016/j.jmii.2020.03.005

171. Wu Y, Xu X, Chen Z, Duan J, Hashimoto K, Yang L, Liu C, Yang C (2020) Nervous system involvement after infection with COVID-19 and other coronaviruses. Brain Behav Immun 87:1822. https://doi.org/10.1016/j.bbi.2020.03.031

172. Xiong W, Mu J, Guo J, Lu L, Liu D, Luo J, Li N, Liu J, Yang D, Gao H, Zhang Y, Lin M, Shen S, Zhang H, Chen L, Wang G, Luo F, Li W, Chen S, He L, Sander JW, Zhou D (2020) New onset neurologic events in people with COVID-19 in 3 regions in China. Neurology 95(11):e1479-e1487. https://doi.org/10.1212/ wnl.0000000000010034

173. Xu H, Zhong L, Deng J, Peng J, Dan H, Zeng X, Li T, Chen Q (2020) High expression of ACE2 receptor of 2019-nCoV on the epithelial cells of oral mucosa. Int J Oral Sci 12(1):8. https://doi. org/10.1038/s41368-020-0074-x

174. Yan CH, Faraji F, Prajapati DP, Boone CE, DeConde AS (2020) Association of chemosensory dysfunction and COVID-19 in patients presenting with influenza-like symptoms. International Forum of Allergy \& Rhinology 10(7):806-813. https://doi.org/ 10.1002/alr.22579

175. Yavarpour-Bali H, Ghasemi-Kasman M (2020) Update on neurological manifestations of COVID-19. Life Sci 257:118063. https://doi.org/10.1016/j.lfs.2020.118063

176. Ylikoski J, Markkanen M, Mäkitie A (2020) Pathophysiology of the COVID-19 - entry to the CNS through the nose. Acta Otolaryngol 140(10):886-889. https://doi.org/10.1080/00016489.2020. 1773533

177. Yu Y, Travaglio M, Popovic R, Leal NS, Martins LM (2021) Alzheimer's and Parkinson's diseases predict different COVID19 outcomes: a UK Biobank Study. Geriatrics (Basel) 6(1):10. https://doi.org/10.3390/geriatrics6010010

178. Zhang Q, Schultz JL, Aldridge GM, Simmering JE, Narayanan NS (2020) Coronavirus disease 2019 case fatality and Parkinson's disease. Movement Disorders: Official Journal of the Movement Disorder Society 35(11):1914-1915. https://doi.org/10. $1002 / \mathrm{mds} .28325$

179. Zhang Y, Xiao M, Zhang S, Xia P, Cao W, Jiang W, Chen H, Ding X, Zhao H, Zhang H, Wang C, Zhao J, Sun X, Tian R, Wu W, Wu D, Ma J, Chen Y, Zhang D, Xie J, Yan X, Zhou X, Liu Z, Wang J, Du B, Qin Y, Gao P, Qin X, Xu Y, Zhang W, Li T, Zhang F, Zhao Y, Li Y, Zhang S (2020) Coagulopathy and antiphospholipid antibodies in patients with Covid-19. N Engl J Med 382(17):e38. https://doi.org/10.1056/NEJMc2007575

180. Zhao H, Shen D, Zhou H, Liu J, Chen S (2020) Guillain-Barré syndrome associated with SARS-CoV-2 infection: causality or coincidence? The Lancet Neurology 19(5):383-384. https://doi. org/10.1016/s1474-4422(20)30109-5

181. Zhao K, Huang J, Dai D, Feng Y, Liu L, Nie S (2020) Acute myelitis after SARS-CoV-2 infection: a case report. medR xiv:2020.2003.2016.20035105. doi:https://doi.org/10.1101/2020. 03.16 .20035105

182. Zheng C, Kar I, Chen CK, Sau C, Woodson S, Serra A, Abboud $\mathrm{H}$ (2020) Multiple sclerosis disease-modifying therapy and the COVID-19 pandemic: implications on the risk of infection and future vaccination. CNS Drugs 34(9):879-896. https://doi.org/ 10.1007/s40263-020-00756-y

183. Zhou J, Liu C, Sun Y, Huang W, Ye K (2021) Cognitive disorders associated with hospitalization of COVID-19: results from an observational cohort study. Brain Behav Immun 91:383-392. https://doi.org/10.1016/j.bbi.2020.10.019

184. Zhu J, Ji P, Pang J, Zhong Z, Li H, He C, Zhang J, Zhao C (2020) Clinical characteristics of 3062 COVID-19 patients: a meta-analysis. J Med Virol 92(10):1902-1914. https://doi.org/ 10.1002/jmv. 25884

185. Zirpe KG, Dixit S, Kulkarni AP, Sapra H, Kakkar G, Gupta R, Bansal AR, Garg A, Dash SK, Gurnani A, Khan A, Khatib KI, Mare PR (2020) Pathophysiological mechanisms and neurological manifestations in COVID-19. Indian Journal of Critical Care Medicine: Peer-Reviewed, Official Publication of Indian Society of Critical Care Medicine 24(10):975-980. https://doi.org/10. 5005/jp-journals-10071-23592

186. Zuhorn F, Omaimen H, Ruprecht B, Stellbrink C, Rauch M, Rogalewski A, Klingebiel R, Schäbitz WR (2020) Parainfectious encephalitis in COVID-19: "The Claustrum Sign.” J Neurol 268(6):1-4. https://doi.org/10.1007/s00415-020-10185-y

Publisher's Note Springer Nature remains neutral with regard to jurisdictional claims in published maps and institutional affiliations. 


\section{Authors and Affiliations}

\section{Saikat Dewanjee ${ }^{1}$ (D) Jayalakshmi Vallamkondu ${ }^{2} \cdot$ Rajkumar Singh Kalra $^{3,11}$ (D) Nagaprasad Puvvada $^{4}$. Ramesh Kandimalla ${ }^{4,5}$ (D) P. Hemachandra Reddy $6,7,8,9,10$ iD}

Jayalakshmi Vallamkondu

vlakshmij@gmail.com

Rajkumar Singh Kalra

rajskalra@hotmail.com

1 Advanced Pharmacognosy Research Laboratory, Department of Pharmaceutical Technology, Jadavpur University, Kolkata 700032, India

2 National Institute of Technology, Warangal 506004, Telangana, India

3 AIST-INDIA DAILAB, National Institute of Advanced Industrial Science \& Technology (AIST), Higashi 1-1-1, Tsukuba 305 8565, Japan

4 Applied Biology, CSIR-Indian Institute of Technology, Uppal Road, Tarnaka, Hyderabad 50000, Telangana, India

5 Department of Biochemistry, Kakatiya Medical College, Warangal 506007, Telangana, India
6 Texas Tech University Health Sciences Center, Lubbock, TX, USA

7 Neuroscience \& Pharmacology, Texas Tech University Health Sciences Center, Lubbock, TX, USA

8 Departments of Neurology, School of Medicine, Texas Tech University Health Sciences Center, Lubbock, TX, USA

9 Public Health Department of Graduate School of Biomedical Sciences, Texas Tech University Health Sciences Center, Lubbock, TX, USA

10 Department of Speech, Language and Hearing Sciences, School Health Professions, Texas Tech University Health Sciences Center, Lubbock, TX, USA

11 Present Address: Immune Signal Unit, Okinawa Institute of Science and Technology Graduate University, 1919-1 Tancha, Onna-son, Okinawa 904-0495, Japan 